\title{
Spatial and temporal variation in statolith and protoconch trace elements as natural tags to track larval dispersal
}

\author{
Danielle C. Zacherl ${ }^{*}$ \\ Department of Ecology, Evolution and Marine Biology, University of California, Santa Barbara, California 93106, USA \\ Present address: Department of Biological Science, PO Box 6850, California State University Fullerton, California 92834-6850, USA
}

\begin{abstract}
Trace elements in larval hard parts may serve as useful tags of natal origin in invertebrate population studies. Using field-collected encapsulated veliger larvae of the marine gastropod Kelletia kelletii, this study examined the extent of spatial and temporal variation in the elemental composition of larval parts formed at the natal source. For both protoconchs and statoliths, results of multivariate analyses of variance (MANOVA) indicated that the elemental compositions show significant among-site and among-region differences. Linear discriminant-function analysis (DFA) correctly classified $89 \%$ of protoconchs and $80 \%$ of statoliths to their region of formation. However, there were significant interannual differences in elemental composition for statoliths at 2 sites and for protoconchs at 3 sites over a 3 yr period. Despite within-site interannual differences, the elemental compositions of hard parts formed during different years resembled one another to such a degree that a DFA generated with a single year's data could correctly predict the region of formation for $83.9 \%$ of statoliths and $82.5 \%$ of protoconchs formed in other years. A comparison of magnesium (Mg), strontium $(\mathrm{Sr})$ and barium $(\mathrm{Ba})$ incorporation patterns with per-site temperature profiles indicated statistically significant positive relationships between temperature and $\mathrm{Mg}$ and $\mathrm{Sr}$ incorporation into protoconchs, and inverse relationships between temperature and $\mathrm{Sr}$ (statoliths) and Ba (both protoconchs and statoliths) incorporation. These data, together with results from other studies, suggest that larval statoliths and protoconchs can meaningfully record variation in the physical and chemical properties of seawater and, hence, have potential as natural tags of natal origin.
\end{abstract}

KEY WORDS: Protoconch $\cdot$ Kelletia kelletii $\cdot$ Larvae $\cdot$ Statolith $\cdot$ Trace elements $\cdot$ LA ICP-MS $\cdot$ Dispersal

\section{INTRODUCTION}

Most marine species produce planktonic larvae that can be advected away from their natal source by oceanic currents. Predicting their dispersal trajectory and destination remains one of the foremost challenges for marine biologists. Reconstructing the trajectory of even passively drifting larvae would be a daunting task. The challenge is magnified even further, since planktonic larvae can exhibit complex swimming behaviors that substantially alter their transport routes (Young 1995, Stobutzki \& Bellwood 1997). In addition, the length of time spent in the planktonic phase is unknown for most species, even for many commercially important fishery species. Collectively, these factors contribute to make predictions about the sources of larvae settling into adult habitat difficult. Yet, identification of the natal source of incoming recruits has tremendous consequences for understanding population connectivity (Crowder et al. 2000), population dynamics and community structure (Caley et al. 1996), and for the design of effective marine protected areas (Warner et al. 2000, Gaines et al. 2003).

We cannot identify natal sources without tracking microscopic larvae through their planktonic phase from their source to their recruitment site. Attempts at 
artificially tagging and tracking larvae using radioactive isotopes, trace elements and chemical stains (e.g. Anastasia et al. 1998) have rarely been successful (e.g. Jones et al. 1999). Advection and diffusion in the water column, coupled with extremely high larval mortality rates during dispersal, make it exceedingly unlikely that tagged larvae will ever be recaptured (Levin 1990, Anastasia et al. 1998). Because of the inherent challenges associated with tag-recapture programs, recent interest has focused on the development of new tools that take advantage of natural environmentally-induced tags in the calcified otoliths (ear stones) of teleost fishes. Fish scientists have examined trace elements present in the otolith to reconstruct migration and dispersal patterns and to identify spawning grounds and juvenile nursery habitats (Gillanders \& Kingsford 1996, Campana 1999, Swearer et al. 1999, Thorrold et al. 2001). The tremendous benefit associated with natural tags such as otoliths is that every larva is effectively tagged, thereby eliminating the problems arising from broad dispersion of tagged larvae (Thorrold et al. 2002).

As with fishes, there is a pressing need to understand processes affecting the recruitment patterns of invertebrate larvae. Importantly, analogous environmentally induced tags exist in mineralized invertebrate hard parts including statoliths, protoconchs, carapaces and larval skeletons. All of these mineralized structures could potentially record environmental history and, hence, act as natural tags of natal origin, yet few studies have done the necessary exploratory work to determine their true utility (but see Dibacco \& Levin 2000 and Zacherl et al. 2003b,c).

Using the trace elemental composition of invertebrate mineralized parts as proxies for natal source relies on the assumption that spatial variation in the physical and chemical properties of seawater will somehow be reflected in the elemental composition of the invertebrate hard part, as has been demonstrated with fish otoliths (Radtke \& Shafer 1992, Secor et al. 1995, Bath et al. 2000). Zacherl et al. (2003c) generated the first such evidence for larval protoconchs and statoliths (both composed of aragonite) of a marine gastropod whelk. In a culture study examining uptake of Ba by Kelletia kelletii larval hard parts, both statoliths and protoconchs incorporated more $\mathrm{Ba}$ as the seawater $\mathrm{Ba}$ concentration increased. Furthermore, there was an inverse temperature effect, with greater Ba incorporation at colder temperatures. Additional culture studies with $K$. kelletii and other molluscan larvae (e.g. the estuarine opisthobranch Alderia modesta) have generated similar results for Sr (Zacherl et al. 2003c) and Mg (D. C. Zacherl unpubl.). The combined results suggest that these calcified structures, like foraminifera tests (Lea et al. 1999) and otoliths (Bath et al. 2000), can reliably record information about the physical and chemical characteristics of seawater.

Using the chemistry of larval statoliths and protoconchs as a tag of natal source also relies upon the existence of spatially unique and temporally stable chemical signatures in the calcified structure of interest. Most studies using natural tags (including otoliths and crab larvae) have focused on species that migrate between river (or estuarine) and coastal habitats, where substantial gradients in salinity, temperature and trace element inputs occur, leading to large variations in tag composition. The search for variation in natural tags at open-coast sites may be complicated by the fact that gradients in oceanographic conditions are more subtle, except at locations of convergence between distinct ocean currents (e.g. Point Conception in central California, USA: Dever et al. 1998) which can be characterized by sharp gradients in water chemistry and temperature. Thus, the degree to which one can use natural tags to resolve dispersal trajectories in open-coast systems is limited by the extent of spatial variation that is reflected in the chemistry of the natural tags.

Even if there is sufficient spatial variation in water chemistry, the utility of using trace metal chemistry to track larval movement depends upon the temporal consistency of the patterns. Both intra-annual variability (Thorrold et al. 1998, Gillanders 2002) and interannual variability (Patterson et al. 1999) in otolith composition may potentially confound spatial variation. Successful application of any natural tag in open coastal waters to identify source population information therefore requires a complete characterization of the spatial and temporal variability in the elemental composition of the otolith.

This study examines whether invertebrate larval hard parts exhibit enough spatial variation in their composition to act as natural tags of natal origin in the open-coast predatory gastropod Kelletia kelletii. Using inductively coupled, plasma mass spectrometry (ICPMS), I evaluate the use of statoliths and protoconchs as natal tags of origin by examining the extent of spatial and temporal variation in the chemistry of encapsulated larval $K$. kelletii protoconchs and statoliths. Specifically, this study examines differences in elemental composition of protoconchs and statoliths formed in 3 regions of $K$. kelletii's range, including coastal sites south and north of Point Conception and a site in the Channel Islands, California, USA (see Fig. 1 \& Table 1). It further examines the extent of variation in site tags both over space (i.e. among sites within regions) and time (i.e. among years) to evaluate the likely constraints on the use of microchemistry as a marker of larval origin. Last, this study examines the relationship between temperature and element incorporation into calcified larval hard parts for $\mathrm{Mg}$, Sr and Ba. 


\section{MATERIALS AND METHODS}

Background and study area. Kelletia kelletii is a common predatory buccinid gastropod occupying rocky subtidal habitats from Baja California, Mexico to central California, USA, where it is a developing fishery resource. It typically occurs on rocky reefs and cobble-sand interfaces in kelp forests, with a vertical distribution from 2 to $70 \mathrm{~m}$ in depth (Rosenthal 1970), but is also found in the intertidal zone. This whelk is a generalist predator that feeds on a variety of mobile and sessile invertebrates. The range of $K$. kelletii spans regions of coastal water with distinctly different temperatures (Fig. 1), circulation patterns (e.g. upwelling regimes) and riverine inputs.

Like many gastropod molluscs, Kelletia kelletii's life history includes females laying benthic egg capsules, with larvae developing into veligers before their release into the plankton. Adults reproduce annually, with egglaying restricted to late spring and summer (late May through August: Rosenthal 1970). The females lay masses of approximately 20 to 80 egg capsules (referred to hereafter as 'broods') on benthic hard substrate, where the embryos develop into encapsulated veliger larvae in approximately 30 to $34 \mathrm{~d}$. Each egg capsule contains between 400 and 2000 larvae. The hatched veligers are planktonic; the length of this life stage is unknown (Rosenthal 1970, Morris et al. 1980). Little is known about the planktonic life of the larvae, although limited culture studies have indicated that the larvae will feed and accrete shell material during their planktonic life (D. C. Zacherl unpubl. data).

SCUBA divers collected egg capsules of Kelletia kelletii from the rocky subtidal habitat at the sites and years indicated in Table 1 \& Fig. 1. Initially, during 1999 and 2000, eggs were collected were at just 2 sites (Ellwood and Monterey) (Diablo Canyon was added in 2000), in order to complete pilot studies on the chemistry of calcified parts of the larvae. These egg-mass samples were archived at $-80^{\circ} \mathrm{C}$ and the decision was made to substantially increase the number of sites per region. During 2001, a more intensive collecting effort ensued. The result was a collection of samples from 2001 which were used for a spatial survey, and archived samples from 1999 and 2000 which were used for a preliminary study on the temporal stability of the chemistry of the calcified structures at selected sites.

Divers collected only 'mature' egg masses in which encapsulated veliger larvae were ready to hatch or were within a few days of hatching. Veliger larvae that are ready to hatch are distinguishable from earlier stages within egg capsules based upon a blackish larval color visible through semi-translucent capsules (D. C. Zacherl unpubl. obs.). Collections were made during June and July, the months of peak capsule abundance in the field. Divers attempted to collect a minimum of 25 broods per site and at least 10 capsules per brood. Broods could be distinguished easily from each other in the field, because egg capsules produced by the same female are linked at the peduncle. Cap-

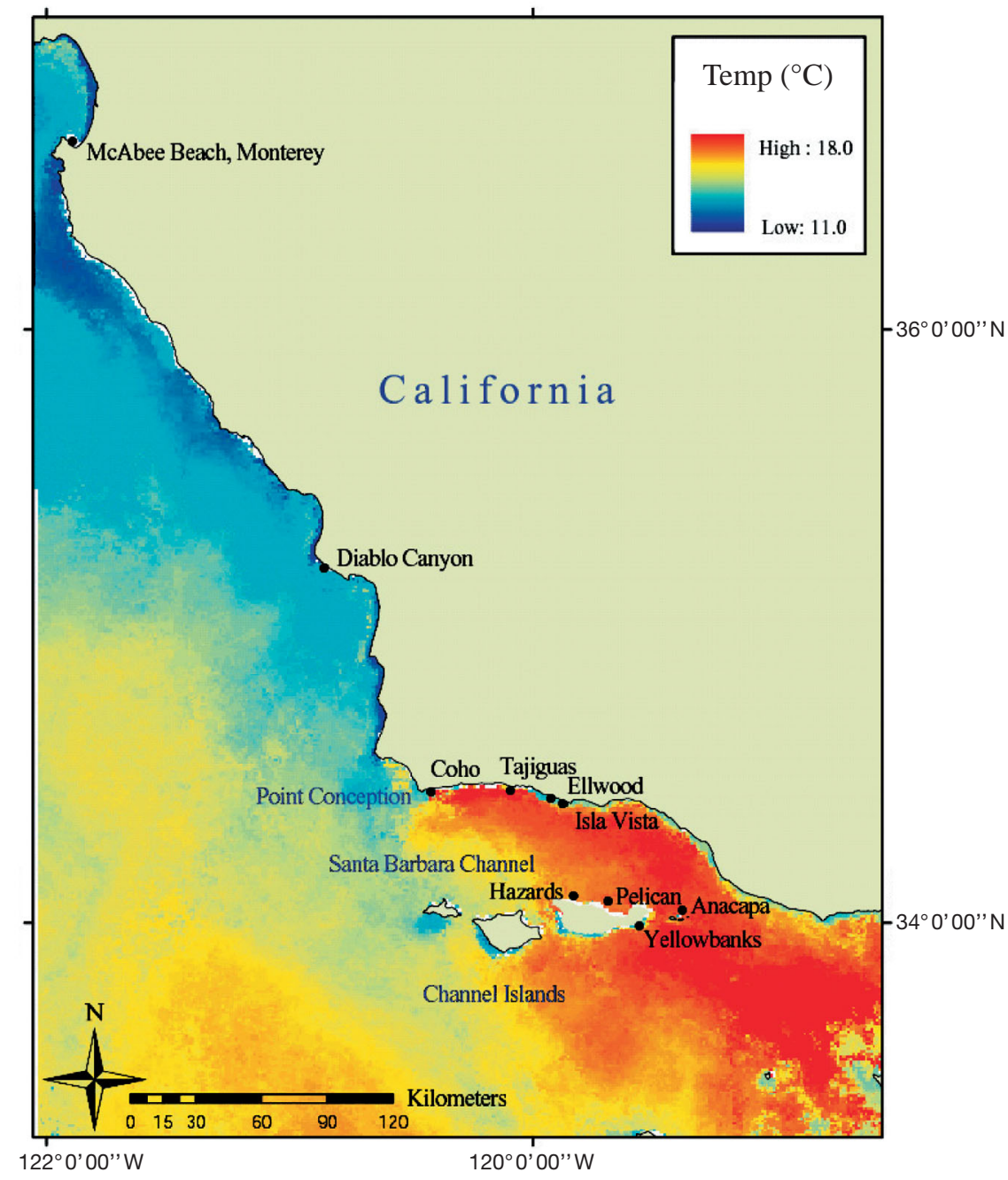

Fig. 1. Map of south-central California, USA, showing central and northern range of Kelletia kelletii, with collection sites. Monthly average sea surface temperature (SST) data from June 2001 are superimposed. Sites north of Point Conception are subject to frequent upwelling of cold nutrient- and metal-rich seawater, while seawater in Santa Barbara Channel is warmer 
sules from individual broods were frozen separately in labeled plastic bags until processing.

Egg-mass collection success varied from site to site (generally as a function of adult whelk abundance). Despite intensive search efforts, divers found no evidence of egg-laying activity at 3 of 4 potential Channel Island sites (Fig. 1): Hazards, Santa Cruz Island $\left(34^{\circ} 32.873^{\prime} \mathrm{N}, 119^{\circ} 50.004^{\prime} \mathrm{W}\right)$, Pelican, Santa Cruz Island $\left(34^{\circ} 23.002^{\prime} \mathrm{N}, 119^{\circ} 42.760^{\prime} \mathrm{W}\right)$, and Anacapa Island $\left(34^{\circ} 13.129^{\prime} \mathrm{N}, 119^{\circ} 21.250^{\prime} \mathrm{W}\right)$, where adult whelk abundances are an order of magnitude lower than at mainland sites (D. C. Zacherl unpubl. data). Therefore, a single site represents the Channel Islands 'region'.

The sites were from 3 regions that could predictably be expected to have differing inputs of trace metals. Variation in upwelling intensity, rainwater runoff, point-source pollution and atmospheric deposition of trace metals should lead to differences in seawater trace metal concentrations. Variation in seawater trace metal concentrations, as well as differences in salinity and temperature, can influence trace metal incorporation into calcified larval structures (Radtke \& Shafer 1992, Secor et al. 1995, Bath et al. 2000). During the summer months, when Kelletia kelletii larvae are developing, sites at Point Conception and northward are influenced mainly by the cold and relatively lowsalinity seawater of the California current. They are in a region marked by frequent upwelling events (Fig. 1). Conversely, coastal waters south of Point Conception are warmer and more saline, with a semi-persistent eddy that flows within the Santa Barbara Channel (Harms \& Winant 1998). Municipal, agricultural and industrial developments all contribute to the content of runoff at all coastal sites. Oceanographic conditions around the Channel Islands are more difficult to characterize. The California current jet meanders back and forth as it progresses south from Point Conception. As a result, its influence on the Channel Islands varies substantially over time (Hayward et al. 1995). In addition, the Channel Islands have no municipal or industrial inputs since they are owned and managed either by the Channel Islands National Park or the Nature Conservancy.

Sites were selected haphazardly, but with prior knowledge of the presence of existing adult whelk populations in the area. Coho, effectively located at Point Conception (1.5 km SE), was difficult to categorize into a region because it lies at the boundary between the northern and southern coastal regions, and is alternately influenced by the southward-flowing California Current and the warm eddy described above. Since the assumption is that spatial variation in the physical and chemical properties of seawater will somehow be reflected in the elemental composition of the analyzed hard parts, subtidal temperature profiles were used to determine whether Coho was primarily influenced by currents originating from the north or south during the time period when larval hard parts were forming.

Surface and subtidal temperature monitoring. To characterize the sites by temperature, both sea-surface and subtidal temperature data were examined. Seasurface temperature data (SST) from all collection sites were obtained as monthly composite SST satellite data from the NOAA Coastwatch for June 2001 (Fig. 1).

Table 1. Kelletia kelletii. Site names, regional assignments, locations, and collection years for egg capsules. Also shown are average ( \pm 1 SD) subtidal temperatures and range of temperatures for the $2 \mathrm{wk}$ period preceding the 2001 collections at each site, the number of broods analyzed for protoconch and statolith elemental composition per year per site, and site-averaged ( \pm SE) metal:Ca ratios for those elements whose incorporation rates were regressed against temperature. R: region, pc: protoconch, st: statolith, N: sites at Point Conception and north; S: sites south of Point Conception; I: sites at Channel Islands; SCI: Santa Cruz Island; *samples lost during cleaning protocol; na: not available

\begin{tabular}{|c|c|c|c|c|c|c|c|c|c|c|}
\hline \multirow[t]{2}{*}{$\mathrm{R}$} & \multirow[t]{2}{*}{ Site } & \multirow[t]{2}{*}{ Location } & \multicolumn{2}{|c|}{ Temperature $\left({ }^{\circ} \mathrm{C}\right)$} & \multirow[t]{2}{*}{ Years } & \multicolumn{2}{|c|}{ No. of broods } & \multirow{2}{*}{$\begin{array}{l}\mathrm{Mg}: \mathrm{Ca} \\
(\mathrm{pc}, \mathrm{st})\end{array}$} & \multirow{2}{*}{$\begin{array}{l}\mathrm{Sr}: \mathrm{Ca} \\
(\mathrm{pc}, \mathrm{st})\end{array}$} & \multirow{2}{*}{$\begin{array}{l}\mathrm{Ba}: \mathrm{Ca} \\
(\mathrm{pc}, \mathrm{st})\end{array}$} \\
\hline & & & Mean \pm SD & Range & & pc & st & & & \\
\hline $\mathrm{N}$ & Monterey & $\begin{array}{l}36^{\circ} 37.09^{\prime} \mathrm{N} \\
121^{\circ} 53.82^{\prime} \mathrm{W}\end{array}$ & $12.83 \pm 0.64$ & 11.9 to 14.1 & $99,00,01$ & $10,10,31$ & $15,10,25$ & $\begin{array}{l}1.10 \pm 0.02, \\
1.88 \pm 0.02\end{array}$ & $\begin{aligned} 2.09 & \pm 0.02 \\
10.10 & \pm 0.08\end{aligned}$ & $\begin{array}{l}2.80 \pm 0.11, \\
5.98 \pm 0.04\end{array}$ \\
\hline $\mathrm{N}$ & $\begin{array}{l}\text { Diablo } \\
\text { Canyon }\end{array}$ & $\begin{array}{l}35^{\circ} 12.267^{\prime} \mathrm{N} \\
120^{\circ} 51.049^{\prime} \mathrm{W}\end{array}$ & $12.53 \pm 0.69$ & 11.8 to 13.7 & 00,01 & 10,20 & 0,25 & $\begin{array}{l}1.08 \pm 0.02, \\
1.89 \pm 0.02\end{array}$ & $\begin{array}{r}2.14 \pm 0.03 \\
10.37 \pm 0.09\end{array}$ & $\begin{array}{l}2.71 \pm 0.14 \\
5.67 \pm 0.05\end{array}$ \\
\hline $\mathrm{N}$ & Coho & $\begin{array}{l}34^{\circ} 26.885^{\prime} \mathrm{N} \\
120^{\circ} 24.110^{\prime} \mathrm{W}\end{array}$ & $12.79 \pm 0.59$ & 11.8 to 13.8 & 01 & 19 & 20 & $\begin{array}{l}1.08 \pm 0.02, \\
1.63 \pm 0.02\end{array}$ & $\begin{array}{l}2.18 \pm 0.03 \\
9.73 \pm 0.09\end{array}$ & $\begin{array}{l}2.31 \pm 0.14 \\
5.79 \pm 0.05\end{array}$ \\
\hline $\mathrm{S}$ & Tajiguas & $\begin{array}{l}34^{\circ} 27.555^{\prime} \mathrm{N} \\
120^{\circ} 05.694^{\prime} \mathrm{W}\end{array}$ & na & & 01 & $10^{*}$ & 15 & $\begin{array}{c}\text { na } \\
2.06 \pm 0.02\end{array}$ & $\begin{array}{c}\text { na } \\
9.89 \pm 0.10\end{array}$ & $\begin{array}{c}\text { na } \\
4.85 \pm 0.06\end{array}$ \\
\hline S & Ellwood & $\begin{array}{l}34^{\circ} 35.610^{\prime} \mathrm{N}, \\
119^{\circ} 55.451^{\prime} \mathrm{W}\end{array}$ & $14.56 \pm 0.82$ & 13.6 to 16.3 & $99,00,01$ & $10,10,24$ & $9,15,25$ & $\begin{array}{l}1.19 \pm 0.02, \\
1.81 \pm 0.01\end{array}$ & $\begin{array}{l}2.25 \pm 0.03 \\
9.56 \pm 0.08\end{array}$ & $\begin{array}{l}2.12 \pm 0.12, \\
5.22 \pm 0.04\end{array}$ \\
\hline S & Isla Vista & $\begin{array}{l}34^{\circ} 24.281^{\prime} \mathrm{N} \\
119^{\circ} 52.051^{\prime} \mathrm{W}\end{array}$ & na & & 01 & 19 & 25 & $\begin{array}{l}1.25 \pm 0.02, \\
1.85 \pm 0.02\end{array}$ & $\begin{array}{l}2.18 \pm 0.03 \\
9.16 \pm 0.08\end{array}$ & $\begin{array}{l}2.46 \pm 0.14 \\
5.67 \pm 0.04\end{array}$ \\
\hline I & $\begin{array}{l}\text { Yellowbanks, } \\
\text { SCI }\end{array}$ & $\begin{array}{l}33^{\circ} 59.478^{\prime} \mathrm{N} \\
119^{\circ} 33.874^{\prime} \mathrm{W}\end{array}$ & $16.37 \pm 0.79$ & 14.9 to 17.2 & 01 & 10 & 15 & $\begin{array}{l}1.33 \pm 0.03, \\
1.92 \pm 0.02\end{array}$ & $\begin{array}{l}2.55 \pm 0.04 \\
9.25 \pm 0.10\end{array}$ & $\begin{array}{l}1.57 \pm 0.19, \\
4.84 \pm 0.06\end{array}$ \\
\hline
\end{tabular}


Subtidal temperature data from a subset of the collection sites (Table 1) were measured by Tidbit ${ }^{\mathrm{TM}}$ loggers maintained by the PISCO (Partnership for Interdisciplinary Studies of Coastal Oceans) research group at the University of California, Santa Barbara. These loggers recorded subtidal seawater temperature at approximately $10 \mathrm{~m}$ depth every $16 \mathrm{~min}$ throughout a 2 wk period preceding collection of egg capsules. Aragonite structures begin forming in encapsulated veliger larvae of Kelletia kelletii around Days 15 to 19, and veligers hatch at Days 30 to 34 . Therefore, subtidal temperature profiles for the $2 \mathrm{wk}$ period preceding collection of pre-hatch encapsulated veliger larvae should characterize temperature regimes experienced by the developing larvae throughout the entire period of aragonite hard-part formation. The monthly composite SST data (Fig. 1) left open the question as to whether Coho should be grouped with northern or southern coastal sites. The subtidal temperature profile (more indicative of conditions experienced by larvae in benthic egg masses), however, indicated that Coho should be grouped with the northern region (Table 1).

Protoconch and statolith analyses. All the following isolation steps were performed in a clean laboratory equipped with Class 100 laminar-flow hoods. All glassware used in the isolation steps was first cleaned with Citranox ${ }^{\mathrm{TM}}$ soap, rinsed 5 times with distilled $\mathrm{H}_{2} \mathrm{O}$ (resistivity $>2 \mathrm{M} \Omega \mathrm{cm}$ ), soaked overnight in $1 \mathrm{~N}$ tracemetal grade $\mathrm{HCl}$, and then rinsed 5 times with ultrapure $\mathrm{H}_{2} \mathrm{O}$ (resistivity $>18.1 \mathrm{M} \Omega \mathrm{cm}$ ).

To isolate protoconch from encapsulated veligers, I thawed a haphazardly selected capsule from each brood per site (10 to 31 broods per site, see Table 1), removed the veligers from the capsules, and dissolved all visible organic tissue away from the shells in an acid-rinsed glass beaker using an equal volume mixture of $30 \% \mathrm{H}_{2} \mathrm{O}_{2}$ buffered in $0.1 \mathrm{~N} \mathrm{NaOH}$ (referred to hereafter as 'peroxide cleaning solution'). Protoconch and statolith material were separated using a $50 \mu \mathrm{m}$ mesh filter. Protoconchs were then rinsed 5 times with ultrapure $\mathrm{H}_{2} \mathrm{O}$. To ensure sufficient shell material for trace element analysis, protoconchs from individual larval snails within a capsule were pooled into groups of 50 and then dry-stored in ultrapure $\mathrm{H}_{2} \mathrm{O}$-rinsed polyethylene vials. To remove any remaining organics from the protoconch, each sample was cleaned with $250 \mu \mathrm{l}$ of the peroxide cleaning solution for $20 \mathrm{~min}$ at $65^{\circ} \mathrm{C}$. Each sample was then rinsed 4 times with ultrapure $\mathrm{H}_{2} \mathrm{O}$, heat-rinsed with ultrapure $\mathrm{H}_{2} \mathrm{O}$ for 20 min at $65^{\circ} \mathrm{C}$, and then rinsed again with ultrapure $\mathrm{H}_{2} \mathrm{O}$. The protoconch samples from Tajiguas were lost during the cleaning steps. Samples were transferred into acidleached polyethylene vials and completely dissolved in $400 \mu \mathrm{l} 0.1 \mathrm{~N}$ nitric acid solution containing enriched ${ }^{135} \mathrm{Ba},{ }^{111} \mathrm{Cd}$ and ${ }^{235} \mathrm{U}$ and internal standards for quan- tification purposes. I assayed for a suite of 10 elements: Calcium (Ca), magnesium (Mg), strontium ( $\mathrm{Sr})$, barium $(\mathrm{Ba})$, lead $(\mathrm{Pb})$, manganese $(\mathrm{Mn})$, cerium $(\mathrm{Ce})$, cadmium $(\mathrm{Cd})$, uranium (U), and zinc $(\mathrm{Zn})$. These elements were chosen because they reliably yielded detectable concentrations in the calcified samples. Samples were blocked by site to minimize the effects of instrument drift on the results, such that 1 sample from each site comprised a block within which samples were randomized. Samples were introduced into a Finnigan Element 2-sector field inductively-coupled plasma mass spectrometer (ICP-MS) using a micro-flow nebulizer at $20 \mu \mathrm{min}^{-1}$. Sensitivity measured $10^{6}$ counts $\mathrm{s}^{-1}$ for $1 \mathrm{ppb}$ indium. Detection limits were calculated for each isotope by calculating the standard deviation (SD) of the intensities of representative isotopes present in $1 \%$ nitric acid $\left(\mathrm{HNO}_{3}\right)$ instrument blanks, and then multiplying the SD by 3 and adding the value to the mean (following Swearer et al. 2003). The resultant value was used as the minimum detectable signal. Intensities of blank-subtracted samples averaged $>1000$ times the detection limit for $\mathrm{Mg}$ and $\mathrm{Sr},>150$ times for $\mathrm{Ba}, \mathrm{Pb}$ and $\mathrm{Zn}$, and $>25$ times the detection limit for Mn, Ce, Cd and U. All metal concentrations were standardized to $\mathrm{Ca}$.

To test for the extent of spatial variability in protoconch elemental composition, I used samples collected during 2001 and compared protoconch element: $\mathrm{Ca}$ ratios among regions and among sites within regions using nested MANOVA (JMP 5.1). I determined whether linear discriminant-function analysis (DFA, S-PLUS 2000 and JMP [SAS] 5.1) could accurately predict each sample's region of formation and site of formation by using a serial-deletion crossvalidation technique. A posteriori contrast comparisons indicated which regions and which sites within regions differed significantly.

For samples spanning multiple years from Diablo, Monterey and Ellwood, MANOVA analyses indicated whether protoconch element:Ca ratios were significantly different among years. I again determined whether DFA could accurately predict each sample's year of formation. A posteriori contrast comparisons indicated which years differed significantly at each site. Before running the MANOVA and DFA, differences in sample weight among years were controlled for by extracting residuals for each element and then using the residuals in the statistical tests.

To isolate larval statoliths from the egg capsules, the same protocols used to isolate protoconchs were employed. Once in the peroxide cleaning solution, statoliths fell to the bottom of the glass beaker. After vigorously swirling the beaker to concentrate the statoliths in the center, they were collected with a pipette and deposited into a glass beaker containing 15 to $20 \mathrm{ml}$ 
ultrapure $\mathrm{H}_{2} \mathrm{O}$ to rinse off the cleaning solution. This rinse step was repeated. Statoliths were then pipetted onto an ultrapure, $\mathrm{H}_{2} \mathrm{O}$-rinsed $20 \times 20 \mathrm{~mm}$ plastic slide. Excess water on the slide was evaporated in a Class 100 laminar flow hood. Statoliths were mounted on double-sided tape (Scotch ${ }^{\mathrm{TM}}$ ) for laser-ablation ICP-MS analysis. The laser attachment to the ICP-MS is a VGTM UV Microprobe Nd:YAG laser that is frequencyquadrupled to $266 \mathrm{~nm}$ with a crater diameter of $20 \mu \mathrm{m}$. Each statolith was completely consumed in ablation. Since some adhesive tape was also ablated with each sample, extensive testing of the tape was completed to quantify the introduction of contaminants to sample analyses. For most elements analyzed, counts from ablations of the adhesive tape yielded values below detection limits. The exception was $\mathrm{Mg}$, where the average of the tape value was detectable, but $<5 \%$ of the sample value. In this system, the carrier gas line was directly connected from the laser sample cell to the nebulizer system of the ICP-MS. When samples were being ablated by the laser and transferred to the spray chamber, the nebulizer was aspirating a $1 \%$ $\mathrm{HNO}_{3}$ solution. Similarly, when standard solutions in a $1 \% \mathrm{HNO}_{3}$ matrix and $1 \% \mathrm{HNO}_{3}$ instrument blanks were aspirated through the nebulizer, the carrier gas flowed from the sample cell. In this manner, the plasma conditions were kept constant during analysis of standards, instrument blanks and samples. The metal:Ca ratio was determined using matrix-matched, solutionbased standards of known metal:Ca ratio and applying a mass bias correction (Rosenthal et al. 1999). I used National Institute of Standards and Technology (NIST612) glass standards as reference materials from which I could estimate the precision of the laser-ablation method. Elemental concentrations were quantified using a matrix-matched standard solution instead of the NIST standard, since the NIST glass lacks the aragonite-dominated matrix of statoliths (see Zacherl et al. 2003c for discussion of the strengths and weaknesses associated with this analytical approach); 10 individual larval statoliths per brood were analyzed. The element menu for statolith analyses comprised $\mathrm{Ca}$, $\mathrm{Mg}, \mathrm{Sr}, \mathrm{Ba}, \mathrm{Pb}, \mathrm{Mn}, \mathrm{Ce}$, and $\mathrm{Zn}$. Uranium and $\mathrm{Cd}$ values were below detection limits in statoliths, and so were dropped from the element list. $\mathrm{Ca}, \mathrm{Sr}, \mathrm{Ba}, \mathrm{Zn}$ and $\mathrm{Pb}$ isotopes were collected in low-resolution mode, and $\mathrm{Ca}, \mathrm{Mg}$ and $\mathrm{Mn}$ in medium resolution mode to avoid isobaric interferences. The abundance of each trace element is expressed as a ratio relative to the amount of $\mathrm{Ca}$, to control for differences in the amount of material analyzed per sample. Detection limits were determined for each element by the same method as for the protoconchs. I then compared blank-subtracted intensities of samples to the detection limit to ensure that sample intensities represented real sample signals.
Intensities of blank-subtracted samples averaged $>100$ times the detection limit for $\mathrm{Ca}, \mathrm{Zn}$ and $\mathrm{Mg}_{1}>50$ times for $\mathrm{Ba}$ and $\mathrm{Sr},>10$ times for $\mathrm{Mn}$ and $>3$ times the detection limit for $\mathrm{Ce}$ and $\mathrm{Pb}$.

To test for the extent of spatial variability in statolith elemental composition, 2001 samples were used to compare statolith element:Ca ratios among regions and among sites within regions using nested MANOVA (statoliths nested within broods within sites within regions). I determined whether DFA could accurately predict each sample's region and site of formation by using a serial-deletion cross-validation technique. To test for temporal variability among years within a site, larval statolith element:Ca ratios were compared among the years 1999 to 2001 at Monterey and at Ellwood using a nested MANOVA (statoliths nested within broods within years). To correct for heteroscedasticity in variances, all statistical tests used log-normalized data. A posteriori contrast comparisons indicated which regions, which sites within regions, and which years within sites differed significantly. I determined whether DFA could accurately predict each sample's year of formation by using a serialdeletion cross-validation technique.

Temperature effects on element incorporation. Based upon laboratory culture studies examining $\mathrm{Ba}$ and $\mathrm{Sr}$ uptake in protoconchs and statoliths, Zacherl et al. (2003c) predicted that larvae developing in cold-water regions should have elevated $\mathrm{Ba}$ and decreased $\mathrm{Sr}$ in their protoconchs and elevated $\mathrm{Ba}$ and $\mathrm{Sr}$ in their statoliths, compared to larvae developing in warmerwater regions. Further, based upon a survey of culture studies with Foraminifera (Nürnberg et al. 1996, Rosenthal et al. 1997, Lea et al. 1999) and preliminary culture studies with Kelletia kelletii larvae (D. C. Zacherl unpubl.), I made an a priori prediction that $\mathrm{Mg}$ would be incorporated into statoliths and protoconchs as a strong positive function of temperature. These predictions were based upon an assumption that other factors affecting metal incorporation into calcified structures do not override the effect of temperature. Least-squares regression (Jmp [SAS) 5.1] of the average subtidal temperature data per site against the average metal:Ca ratio per site (Table 1) was used to test these predictions.

\section{RESULTS}

\section{Protoconchs}

Trace element concentrations in near-hatch Kelletia kelletii larval protoconchs differed significantly among regions (nested MANOVA, p $<0.0001$, Table 2) and among sites within regions $(\mathrm{p}<0.0001)$. A posteriori 
Table 2. Kelletia kelletii. Nested MANOVA (Pillai's trace) test statistics for comparisons of protoconch elemental compositions among sites nested within regions of 2001. Also shown are results of a posteriori pair-wise comparisons for differences between each region, and differences between sites within regions, using contrasts of least-squares means. For pair-wise comparisons of regions, Bonferroni-corrected $\alpha^{\prime}=$ $0.05 / 3=0.017$; for pair-wise comparisons of sites, Bonferronicorrected $\alpha^{\prime}=0.05 / 4=0.0125$. NumDF: numerator degrees of freedom; DenDF: denominator degrees of freedom

\begin{tabular}{|lccccc|}
\hline Classification & Pillai & $F$ & NumDF & DenDF & $p>F$ \\
\hline Region & 1.23 & 19.40 & 18 & 220 & $<0.0001$ \\
Sites (region) & 0.61 & 3.18 & 27 & 333 & $<0.0001$ \\
Between-region comparisons & & & \\
North-South & 1.45 & 17.55 & 9 & 109 & $<0.0001$ \\
North-Island & 2.20 & 26.60 & 9 & 109 & $<0.0001$ \\
South-Island & 1.58 & 19.19 & 9 & 109 & $<0.0001$ \\
Between-site, within-region comparisons & & \\
Monterey-Diablo & 0.40 & 4.90 & 9 & 109 & $<0.0001$ \\
Monterey-Coho & 0.46 & 5.58 & 9 & 109 & $<0.0001$ \\
Diablo-Coho & 0.09 & 1.11 & 9 & 109 & 0.3647 \\
Ellwood-Isla Vista & 0.21 & 2.58 & 9 & 109 & 0.0099 \\
\hline
\end{tabular}
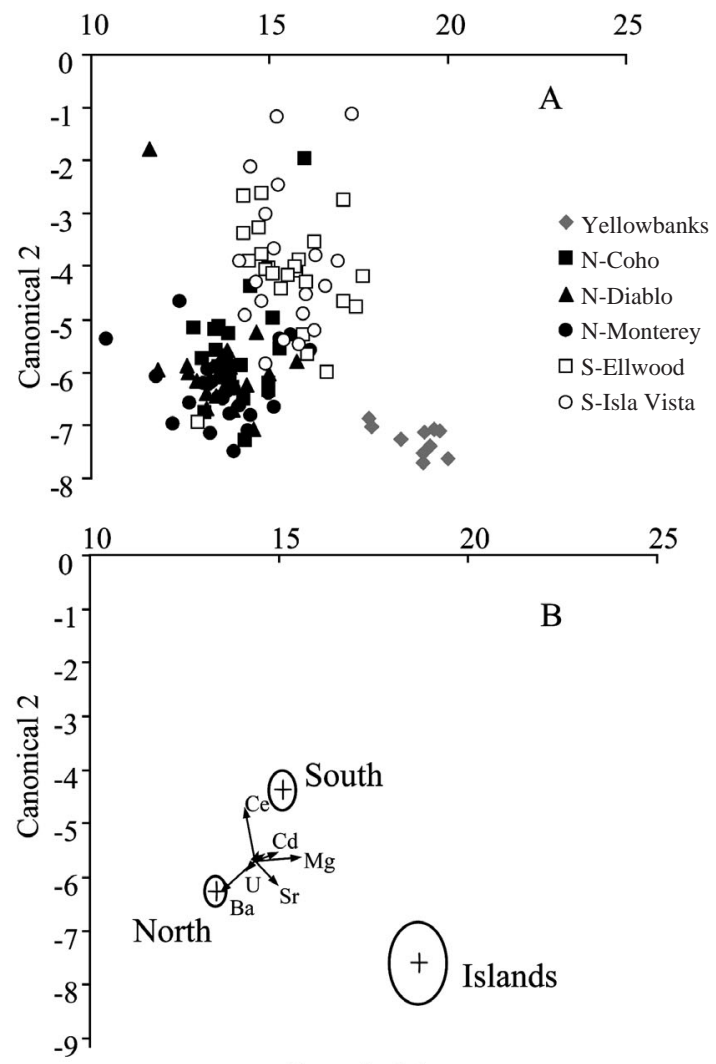

Canonical 1

Fig. 2. Kelletia kelletii. Discriminant scores summarizing variation in elemental composition of protoconchs from encapsulated larvae formed during summer 2001 in 3 different regions: north (black symbols) versus south (open symbols) of Point Conception versus the Channel Islands (grey symbols). (A) Scatterplot of canonical scores; (B) biplot rays of standardized discriminant functions, where vectors indicate relative contributions of elements contrast tests demonstrated significant differences in the elemental composition of protoconchs from the region at Point Conception and north versus the coastal region south of Point Conception versus the site at the Channel Islands $(\mathrm{p}<0.0001$ for all pair-wise comparisons). From linear discriminant-function analysis (DFA), the canonical variate plot indicated that samples clustered in canonical space according to their regional origin (Fig. 2A). Samples from the Channel Islands separated out on Canonical Factor 1, while the other regions were separated on Canonical Factor 2. The magnitude of the vectors of the standardized discriminant functions (Fig. 2B) indicated that the $\mathrm{Ce}: \mathrm{Ca}, \mathrm{Ba}: \mathrm{Ca}, \mathrm{Mg}: \mathrm{Ca}$ and $\mathrm{Sr}: \mathrm{Ca}$ ratios played important roles in discriminating samples among regions. Protoconchs formed in the cold-upwelling region at Point Conception and north (see Fig. 1 and Table 1 for temperature profiles) were characterized by elevated $\mathrm{Ba}: \mathrm{Ca}$ and depressed $\mathrm{Mg}: \mathrm{Ca}, \mathrm{Sr}: \mathrm{Ca}$ and $\mathrm{Mn}: \mathrm{Ca}$ ratios compared with the warmer-water southern regions (Fig. 3). Protoconchs developing at the island site showed the lowest $\mathrm{Pb}: \mathrm{Ca}$ and $\mathrm{Ce}: \mathrm{Ca}$ and the highest $\mathrm{Mg}: \mathrm{Ca}$ and $\mathrm{Sr}: \mathrm{Ca}$ ratios.

Finally, DFA was applied to determine whether a sample's elemental composition could correctly predict its region and site of formation. Using a serial-deletion cross-validation technique, DFA classified $89 \%$ of all samples (Table 3) correctly into their region of formation. To summarize, it was possible to distinguish among regions based on protoconch chemistry with only $11 \%$ error.

Table 3. Kelletia kelletii. Cross-validation accuracy (\%) from linear discriminant analyses classifying $K$. kelletii protoconchs formed in 2001 to region and site of formation based on elemental composition. Columns identify region and site of protoconch formation; rows identify percent of samples classified into each region and site based upon canonical scores. N: sites at Point Conception and north; S: sites south of Point Conception; I: sites at Channel Islands

\begin{tabular}{|lrrrrrr}
\hline Classification & \multicolumn{5}{c}{ Region/site of formation } \\
\hline Region & $\mathrm{N}$ & \multicolumn{2}{c}{$\mathrm{S}$} & $\mathrm{I}$ \\
\cline { 2 - 7 } $\mathrm{N}$ & 88.6 & & 14.0 & & 0.0 \\
$\mathrm{~S}$ & 11.4 & & 86.0 & & 0.0 \\
$\mathrm{I}$ & 0.0 & & 0.0 & & 100.0 \\
Overall accuracy & $89 \%$ & & & & & \\
& & & & & & \\
Site & $\mathrm{Y}$ & $\mathrm{IV}$ & $\mathrm{E}$ & $\mathrm{C}$ & $\mathrm{D}$ & $\mathrm{M}$ \\
& & & & & & \\
Yellowbanks (Y) & 100.0 & 0.0 & 0.0 & 0.0 & 0.0 & 0.0 \\
Isla Vista (IV) & 0.0 & 52.6 & 12.5 & 5.3 & 5.0 & 3.2 \\
Ellwood (E) & 0.0 & 31.6 & 83.3 & 0.0 & 5.0 & 3.2 \\
Coho (C) & 0.0 & 15.8 & 0.0 & 68.4 & 20.0 & 0.0 \\
Diablo (D) & 0.0 & 0.0 & 0.0 & 21.0 & 60.0 & 12.9 \\
Monterey (M) & 0.0 & 0.0 & 4.2 & 5.3 & 10.0 & 80.7 \\
Overall accuracy & $65 \%$ & & & & & \\
\end{tabular}



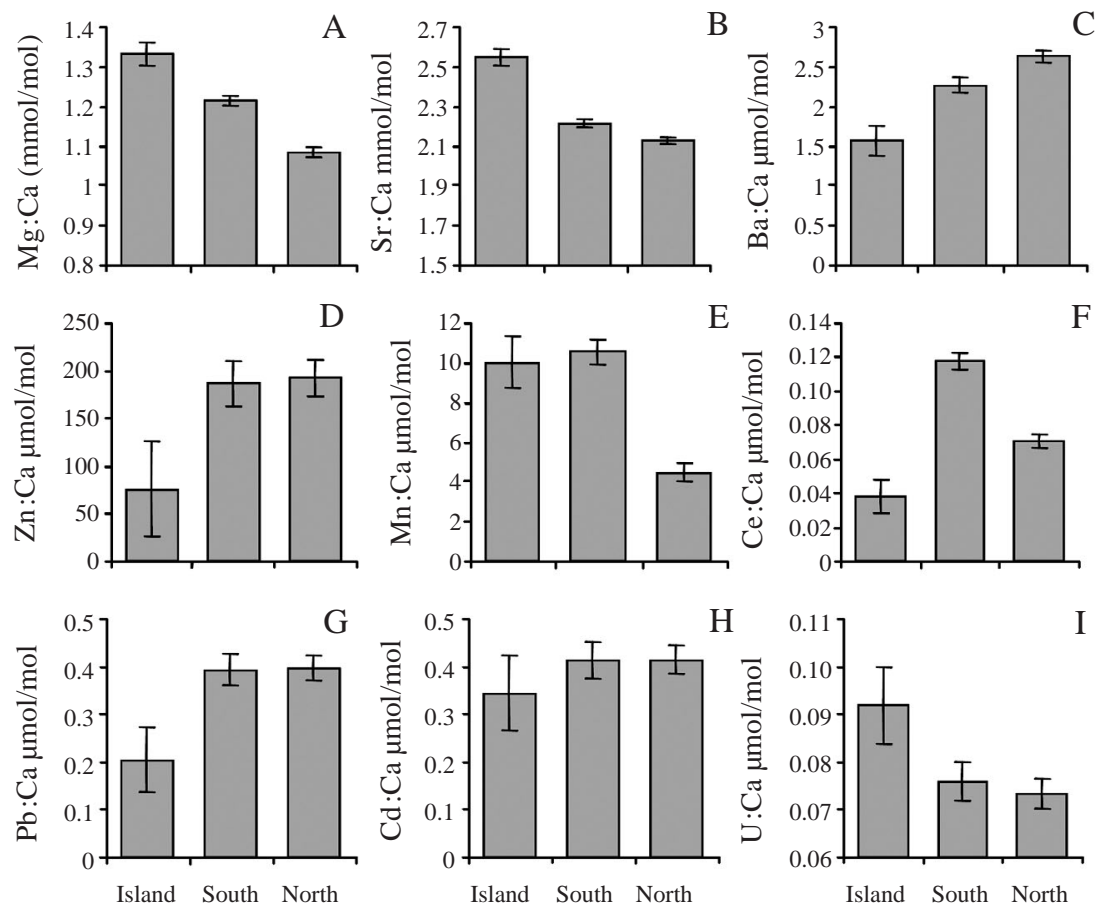

Fig. 3. Kelletia kelletii. Mean $( \pm 1 \mathrm{SE})$ values of elements used in discriminantfunction analysis (DFA) to characterize natal signals in protoconchs of encapsulated larvae for 3 regions during summer 2001: north versus south of Point Conception versus the Channel Islands. Elements expressed as ratios to $\mathrm{Ca}$

To assess the spatial extent of variability in protoconch elemental composition at finer scales, I also compared sites within regions using a posteriori contrast tests. With 1 exception (Diablo versus Coho), these between-site comparisons showed significant differences (Table 2). The predictive capacity of the DFA performed substantially better than would be predicted by random guessing $(16.7 \%)$, with $65 \%$ of all samples correctly assigned to their site of formation (Table 3). While the percentage of correct assignments did diminish compared to regional assignments, the misclassified samples were most often assigned to a nearest neighbor. For example, while only $52.6 \%$ of samples from Isla Vista were correctly classified to their site of formation, $31.6 \%$ were incorrectly classified to Isla Vista's nearest neighbor, Ellwood. In addition, classification success was quite high for some sites, i.e. Monterey $(80.7 \%)$, Yellowbanks $(100 \%)$, and Ellwood $(83.3 \%)$.

Trace element concentrations in near-hatch Kelletia kelletii larval protoconchs also differed significantly among years at all 3 sites tested, i.e. Ellwood, Diablo and Monterey (Figs. 4 \& 5, Tables 4 \& 5). For Ellwood, Hotelling's $T$-squared test shows that the elemental composition of protoconchs formed in 2000 differed significantly from the composition of those formed in 1999 and 2001 (Table 4). The magnitude of the vectors of the standardized discriminant functions (Fig. 4C) indicated that the $\mathrm{Pb}: \mathrm{Ca}$, $\mathrm{Ba}: \mathrm{Ca}, \mathrm{Ce}: \mathrm{Ca}$ and U:Ca ratios played important roles in discriminating Ellwood samples among years. Residual analyses of the elemental compositions of protoconchs showed that elevated $\mathrm{Ba}: \mathrm{Ca}$ and $\mathrm{U}: \mathrm{Ca}$ and lower Mg:Ca and $\mathrm{Pb}: \mathrm{Ca}$ ratios distinguished 2000 from the other years (Fig. 5A). The crossvalidation accuracy, however, averaged $64 \%$ (Table 5), indicating that although protoconchs formed in different years can be statistically distinguished, practical tools like DFA cannot as effectively assign unknowns to their correct year. Further, Hotelling's T-squared test showed that protoconchs from 1999 and 2001 were chemically indistinguishable $(p=0.2450$, Table 4, Fig. 4A); this is also evident in the poor cross-validation accuracy of protoconchs formed during 1999 (Table 5), when only $40 \%$ of samples were classified correctly. At Diablo, protoconchs formed during 2001 were chemically distinguishable from those formed in $2000(\mathrm{p}=0.0014$, Table 4). Residuals from the $\mathrm{Cd}: \mathrm{Ca}, \mathrm{Ba}: \mathrm{Ca}$ and $\mathrm{Ce}: \mathrm{Ca}$ ratios contributed to generating the significant difference (Fig. 5B). Similarly, in Monterey, protoconch samples collected in 2001 differed significantly from those in the previous $2 \mathrm{yr}(\mathrm{p}<0.0001$ for both pair-wise comparisons: Table 4 \& Fig. 4B), and cross-validation

Table 4. Kelletia kelletii. MANOVA (Pillai's trace) test statistics for comparisons of protoconch elemental compositions among years at 3 sites. Also shown are results from pairwise comparisons for differences between each year for each site using Hotelling's $T$-squared test. For pair-wise comparisons, Bonferroni-corrected $\alpha^{\prime}=0.05 / 3=0.017$. Diablo was sampled only during 2000 and 2001, therefore no pair-wise comparisons are provided. Abbreviations as in Table 2

\begin{tabular}{|lcrrrr|}
\hline Site/year & Pillai & $F$ & NumDF & DenDF & $p>F$ \\
\hline Ellwood & 0.86 & 3.09 & 18 & 74 & 0.0003 \\
Diablo & 0.76 & 5.62 & 9 & 16 & 0.0014 \\
Monterey & 1.07 & 4.45 & 18 & 70 & $<0.0001$ \\
$\begin{array}{l}\text { Pair-wise comparisons, Ellwood } \\
\text { 1999-2000 }\end{array}$ 6.89 & 9 & 36 & $<0.0001$ \\
$1999-2001$ & 1.35 & 9 & 36 & 0.2450 \\
2000-2001 & 6.28 & 9 & 36 & $<0.0001$ \\
Pair-wise comparisons, Monterey & & \\
1999-2000 & 1.99 & 9 & 34 & 0.0722 \\
1999-2001 & 7.75 & 9 & 34 & $<0.0001$ \\
$2000-2001$ & 6.58 & 9 & 34 & $<0.0001$ \\
\hline
\end{tabular}


Table 5. Kelletia kelletii. Cross-validation accuracy (\%) from linear discriminant-function analysis classifying protoconchs to year of formation based on elemental composition. Columns identify year of protoconch formation, rows identify percent of samples per site classified into each year based upon canonical scores

\begin{tabular}{|lrcr|}
\hline Classification & \multicolumn{3}{c|}{ Year of formation } \\
& 1999 & 2000 & 2001 \\
\hline Ellwood & & & \\
1999 & 40.0 & 0.0 & 18.5 \\
2000 & 0.0 & 70.0 & 11.1 \\
2001 & 60.0 & 30.0 & 70.4 \\
Overall accuracy =64\% & & & \\
Diablo & & & \\
2000 & na & 70.0 & 12.5 \\
2001 & na & 30.0 & 87.5 \\
Overall accuracy $=81 \%$ & & & \\
Monterey & & & \\
1999 & 60.0 & 20.0 & 0.0 \\
2000 & 30.0 & 70.0 & 12.0 \\
2001 & 10.0 & 10.0 & 88.0 \\
Overall accuracy $=78 \%$ & & & \\
\hline
\end{tabular}

accuracy improved (Table 5), with $88 \%$ of samples from Monterey in 2001 classified correctly. The magnitude of the vectors of the standardized discriminant functions (Fig. 4D) indicated that $\mathrm{Pb}: \mathrm{Ca}, \mathrm{Ba}: \mathrm{Ca}, \mathrm{Ce}: \mathrm{Ca}$ and $\mathrm{Mg}: \mathrm{Ca}$ ratios played important roles in discrimi- nating Monterey samples among years. Elevated $\mathrm{Mg}: \mathrm{Ca}$ and $\mathrm{Sr}: \mathrm{Ca}$ and lower $\mathrm{Pb}$ :Ca ratios distinguished 2001 samples from those of other years (Fig. 5C). Overall, DFA correctly classified $64 \%$ of Ellwood samples, $81 \%$ of Diablo samples, and $78 \%$ of Monterey samples to their correct year of formation. These results demonstrate that protoconch elemental tags formed within a site can vary significantly in their chemical composition among years.

\section{Statoliths}

Trace element concentrations in near-hatch Kelletia kelletii larval statoliths differed significantly among regions (nested MANOVA, p < 0.0001, Table 6), among sites within regions $(\mathrm{p}<0.0001)$, and among broods within sites $(\mathrm{p}<0.0001)$. A posteriori contrast tests demonstrated highly significant differences in the elemental composition of statoliths from the region at Point Conception and north, versus the coastal region south of Point Conception, versus the site at the Channel Islands ( $p<0.0001$ for all pair-wise comparisons).

Using DFA, I generated a canonical variate plot using all statolith samples. The statolith DFA indicated that samples from all 3 regions occupied different but overlapping locations in canonical space (Fig. 6A). The
Fig. 4. Kelletia kelletii. Discriminant scores summarizing variation in elemental composition of protoconchs formed over $3 \mathrm{yr}$ at Ellwood and Monterey. Scatterplot of canonical scores: (A) Ellwood; (B) Monterey. Biplot rays of standardized discriminant functions: (C) Ellwood; (D) Monterey. Vectors indicate relative contributions of elements to canonical scores

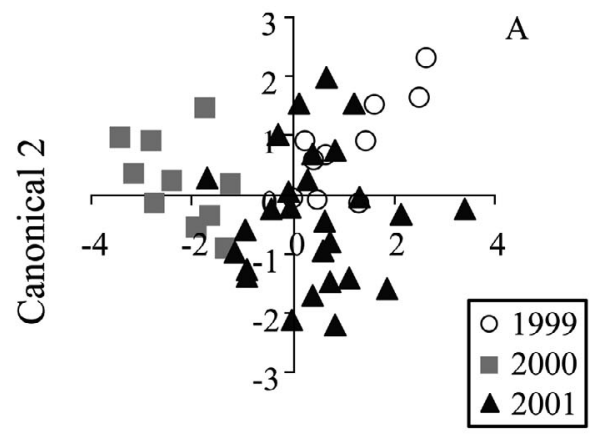

Canonical 1

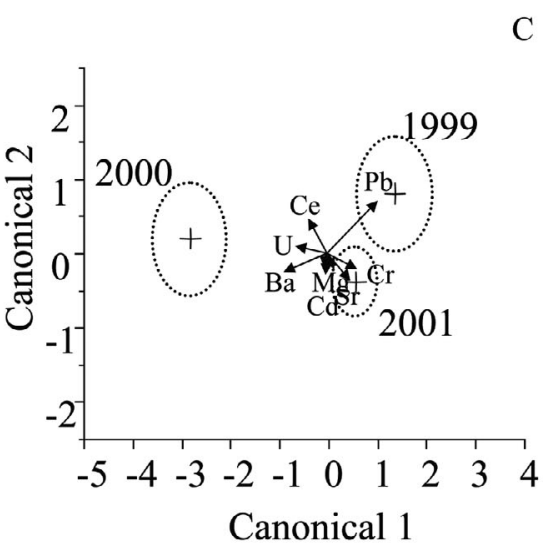

$\mathrm{C}$

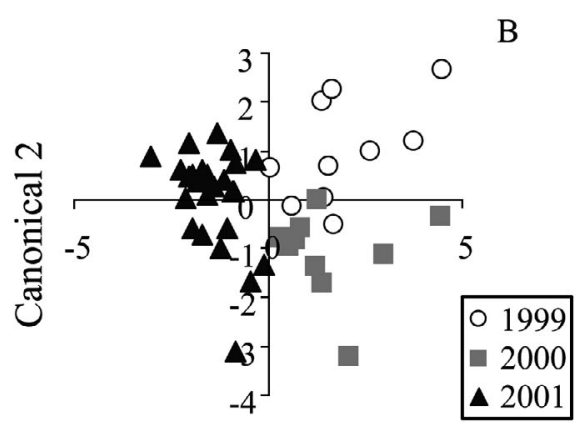

Canonical 1

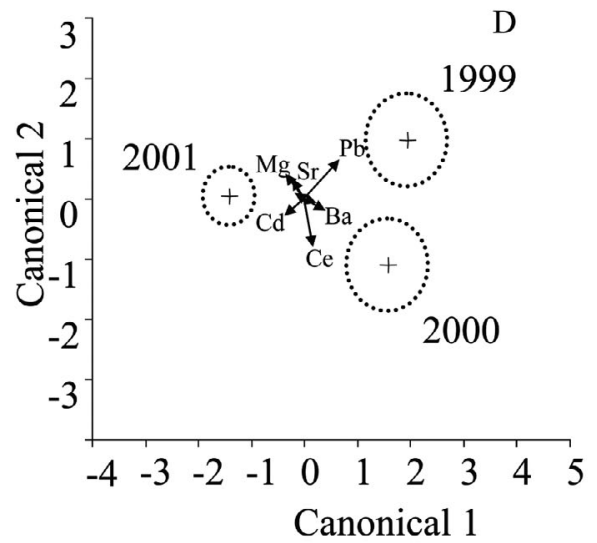




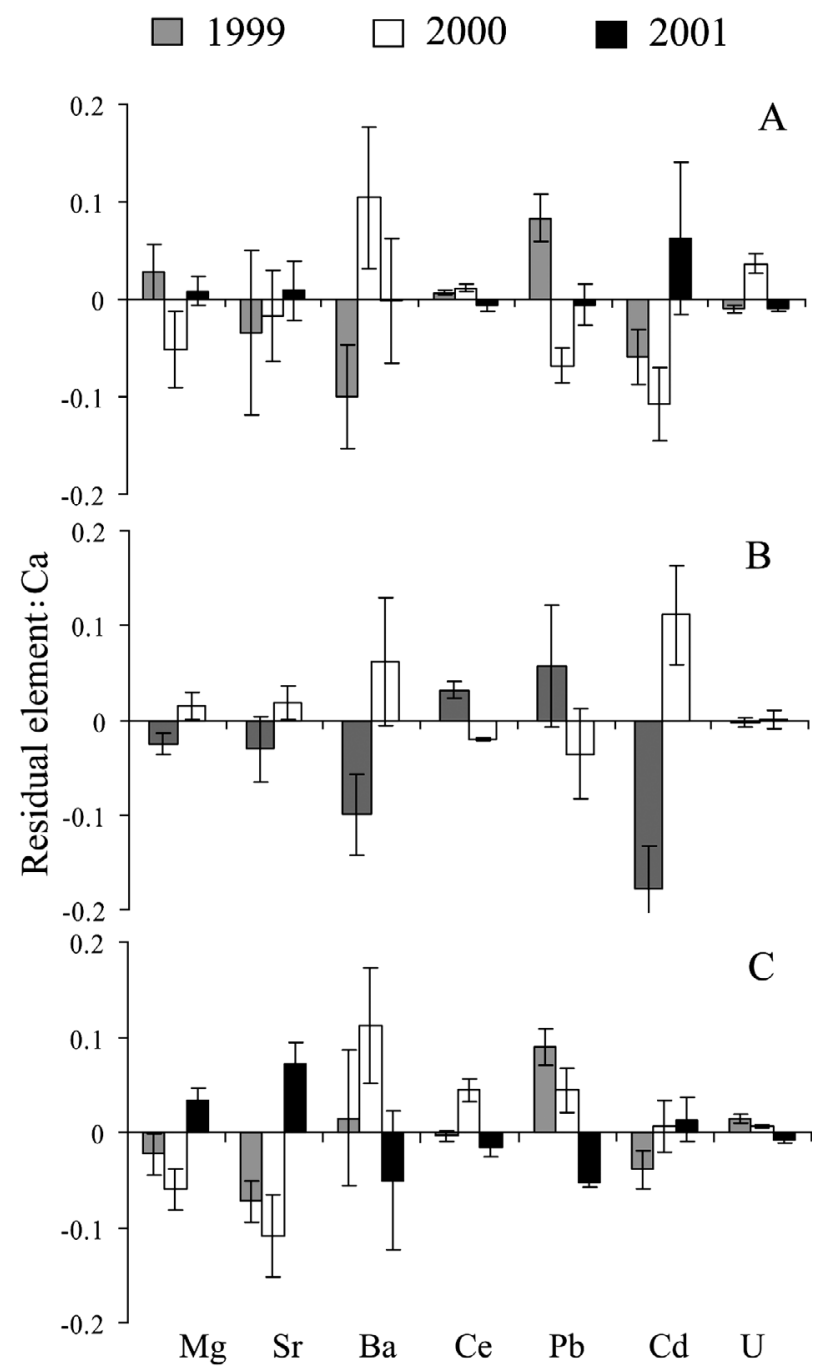

Fig. 5. Kelletia kelletii. Residual mean values of elements used in DFA to characterize natal signals in protoconchs of encapsulated larvae for $3 \mathrm{yr}$ at (A) Ellwood, (B) Diablo, (C) Monterey. Elemental concentrations expressed as ratios to Ca. Units are residuals after effect of sample weight on element:Ca ratio was removed

magnitudes of the vectors of the standardized discriminant functions (Fig. 6B) reflect the important roles played by $\mathrm{Mn}: \mathrm{Ca}, \mathrm{Ce}: \mathrm{Ca}, \mathrm{Pb}: \mathrm{Ca}$ and $\mathrm{Zn}: \mathrm{Ca}$ ratios in discriminating statolith samples among regions. As with the protoconchs, statoliths formed in the coldupwelling region at Point Conception and north contained higher $\mathrm{Ba}: \mathrm{Ca}$ and lower $\mathrm{Mg}: \mathrm{Ca}$ and $\mathrm{Mn}: \mathrm{Ca}$ ratios than the warmer-water southern regions (Fig. 7). The island site again showed the lowest $\mathrm{Pb}: \mathrm{Ca}$ and $\mathrm{Ce}: \mathrm{Ca}$ and the highest Mg:Ca ratios. The Sr:Ca pattern in the statoliths, highest in the north and lowest at the islands, was exactly opposite that in the protoconchs (cf. Figs. 3B \& 7B).

Finally, DFA determined whether a statolith's elemental composition could be used to correctly predict
Table 6. Nested MANOVA (Pillai's trace) test statistics for comparisons of statolith elemental compositions among broods nested within sites nested within regions from 2001. Also shown are results from a posteriori pair-wise comparisons for differences between each region, and differences between sites within regions using contrasts of least-squares means. For pair-wise comparisons of regions, Bonferroni-corrected $\alpha^{\prime}=0.05 / 3=0.017$; for pair-wise comparisons of sites, Bonferroni-corrected $\alpha^{\prime}=0.05 / 6=0.0083$. Abbreviations as in Table 2

\begin{tabular}{|lrrrrr|}
\hline Parameter & Pillai & $F$ & NumDF & DenDF & $\mathrm{p}>F$ \\
\hline Region & 1.32 & 354.39 & 14 & 2568 & $<0.0001$ \\
Site (region) & 1.97 & 178.55 & 28 & 5144 & $<0.0001$ \\
Brood (site, region) & 3.62 & 9.99 & 966 & 9023 & $<0.0001$ \\
Between-region comparisons & & & \\
North-South & 2.87 & 526.19 & 7 & 1283 & $<0.0001$ \\
North-Island & 1.28 & 234.46 & 7 & 1283 & $<0.0001$ \\
South-Island & 2.14 & 392.78 & 7 & 1283 & $<0.0001$ \\
Between-site, within-region comparisons & & \\
Monterey-Diablo & 1.18 & 216.07 & 7 & 1283 & $<0.0001$ \\
Monterey-Coho & 2.24 & 410.53 & 7 & 1283 & $<0.0001$ \\
Diablo-Coho & 1.14 & 208.77 & 7 & 1283 & $<0.0001$ \\
Ellwood-Isla Vista & 0.40 & 73.72 & 7 & 1283 & $<0.0001$ \\
Ellwood-Tajiguas & 2.84 & 520.43 & 7 & 1283 & $<0.0001$ \\
Tajiguas-Isla Vista & 2.72 & 499.38 & 7 & 1283 & $<0.0001$ \\
\hline
\end{tabular}

its region and site of formation. A serial-deletion crossvalidation, DFA classified $80 \%$ of all statolith samples correctly into their region of formation (Table 7). To summarize, DFA was able to distinguish among regions based on statolith chemistry.

To better assess the spatial extent of variability in statolith elemental composition, I also compared sites within regions using a posteriori contrast tests. All

Table 7. Kelletia kelletii. Cross-validation accuracy (\%) from linear discriminant analyses classifying statoliths formed in 2001 to region and site of formation. Columns identify region and site of statolith formation; rows identify percent of samples classified into each region and site based upon canonical scores. N: sites at Point Conception and north; S: sites south of Point Conception; I: sites at Channel Islands

\begin{tabular}{|c|c|c|c|c|c|c|c|}
\hline \multirow{2}{*}{$\frac{\text { Classification }}{\text { Region }}$} & \multicolumn{7}{|c|}{ Region/site of formation } \\
\hline & \multicolumn{2}{|c|}{$\mathrm{N}$} & \multicolumn{3}{|c|}{$\mathrm{S}$} & \multicolumn{2}{|r|}{ I } \\
\hline $\mathrm{N}$ & & 4.7 & & 9.9 & & & 30.6 \\
\hline $\mathrm{S}$ & & 1.2 & & 89.0 & & & 6.2 \\
\hline I & & 4.1 & & 1.1 & & & 63.2 \\
\hline \multicolumn{8}{|c|}{ Overall accuracy = 80\% } \\
\hline Site & $\mathrm{Y}$ & IV & $\mathrm{E}$ & $\mathrm{T}$ & $\mathrm{C}$ & $\mathrm{D}$ & M \\
\hline Yellowbanks (Y) & 79.4 & 2.0 & 0.8 & 0.0 & 0.5 & 4.8 & 6.4 \\
\hline Isla Vista (IV) & 0.0 & 66.0 & 23.6 & 12.7 & 4.5 & 9.2 & 0.0 \\
\hline Ellwood (E) & 1.3 & 19.2 & 60.4 & 4.0 & 12.5 & 0.8 & 0.0 \\
\hline Tajiguas (T) & 1.3 & 1.2 & 1.6 & 72.7 & 1.0 & 11.6 & 0.0 \\
\hline Coho (C) & 4.0 & 8.8 & 10.8 & 3.3 & 73.0 & 6.0 & 2.4 \\
\hline Diablo (D) & 10.7 & 2.8 & 2.8 & 7.3 & 5.0 & 60.4 & 6.4 \\
\hline Monterey (M) & 3.3 & 0.0 & 0.0 & 0.0 & 3.5 & 7.2 & 84.8 \\
\hline
\end{tabular}


Table 8. Kelletia kelletii. Nested MANOVA (Pillai's trace) test statistics for comparisons of statolith elemental compositions among years at Ellwood and Monterey. Also shown are results from a posteriori pair-wise comparisons for differences between each region, and differences between sites within regions using contrasts of least-squares means. For pair-wise comparisons of years, Bonferroni-corrected $\alpha^{\prime}=0.05 / 3=0.017$. Abbreviations as in Table 2

\begin{tabular}{|c|c|c|c|c|c|}
\hline Site/year & Pillai & $F$ & NumDF & DenDF & $\mathrm{p}>F$ \\
\hline Ellwood-year & 1.60 & 291.27 & 12 & 874 & $<0.0001$ \\
\hline Brood (year) & 3.16 & 10.67 & 276 & 2646 & $<0.0001$ \\
\hline Monterey-year & 1.19 & 107.03 & 12 & 882 & $<0.0001$ \\
\hline Brood (year) & 2.99 & 9.43 & 282 & 2670 & $<0.0001$ \\
\hline \multicolumn{6}{|c|}{ Pair-wise comparisons - Ellwood } \\
\hline $1999-2000$ & 3.79 & 275.73 & 6 & 436 & $<0.0001$ \\
\hline $2000-2001$ & 3.63 & 263.44 & 6 & 436 & $<0.0001$ \\
\hline 1999-2001 & 6.26 & 454.96 & 6 & 436 & $<0.0001$ \\
\hline \multicolumn{6}{|c|}{ Pair-wise comparisons - Monterey } \\
\hline 1999-2000 & 0.38 & 27.61 & 6 & 440 & $<0.0001$ \\
\hline $2000-2001$ & 7.71 & 565.28 & 6 & 440 & $<0.0001$ \\
\hline 1999-2001 & 11.66 & 854.94 & 6 & 440 & $<0.0001$ \\
\hline
\end{tabular}

between-site comparisons showed significant differences ( $p<0.0001$, Table 6). Again, the predictive capacity of the DFA was diminished surprisingly little (as with the protoconchs), with $70.2 \%$ of all samples correctly assigned to their site of formation (Table 7). While the percentage of correct assignments did diminish, compared to regional assignments, the misclassified samples were most often assigned to other sites within the region. In addition, classification success was again high for some sites, i.e. Monterey $(84.8 \%)$, and Yellowbanks (79.4\%).

Within sites, trace element concentrations in nearhatch Kelletia kelletii larval statoliths differed significantly among broods (nested MANOVA, $\mathrm{p}<0.0001$, Table 6).

Trace element concentrations in near-hatch Kelletia kelletii larval statoliths also differed significantly among years at 2 sites tested, Ellwood and Monterey (Figs. 8 \& 9 and Table 8), with among-brood differences also present (nested MANOVA, p $<0.0001$ at both sites). At Ellwood, a posteriori pair-wise comparisons showed that the elemental composition of statoliths differed significantly for all years. The magnitude of the vectors of the standardized discriminant functions (Fig. 8C) indicated that $\mathrm{Pb}: \mathrm{Ca}, \mathrm{Ce}: \mathrm{Ca}, \mathrm{Ba}: \mathrm{Ca}$ and $\mathrm{Zn}$ :Ca ratios played important roles in discriminating statolith samples among years at Ellwood. Analyses of the elemental compositions of statoliths per year showed lowest $\mathrm{Mg}: \mathrm{Ca}$ and $\mathrm{Zn}: \mathrm{Ca}$ and highest $\mathrm{Mn}: \mathrm{Ca}$ and $\mathrm{Pb}: \mathrm{Ca}$ ratios during 1999. Ellwood statoliths from the year 2000 had the highest $\mathrm{Mg}: \mathrm{Ca}, \mathrm{Ba}: \mathrm{Ca}, \mathrm{Ce}: \mathrm{Ca}$ and Zn:Ca ratios (Fig. 9A-G) relative to other years. Statoliths formed in different years, then, can be statistically distinguished and practical tools like DFA can effectively separate them. In Monterey, statolith sam-

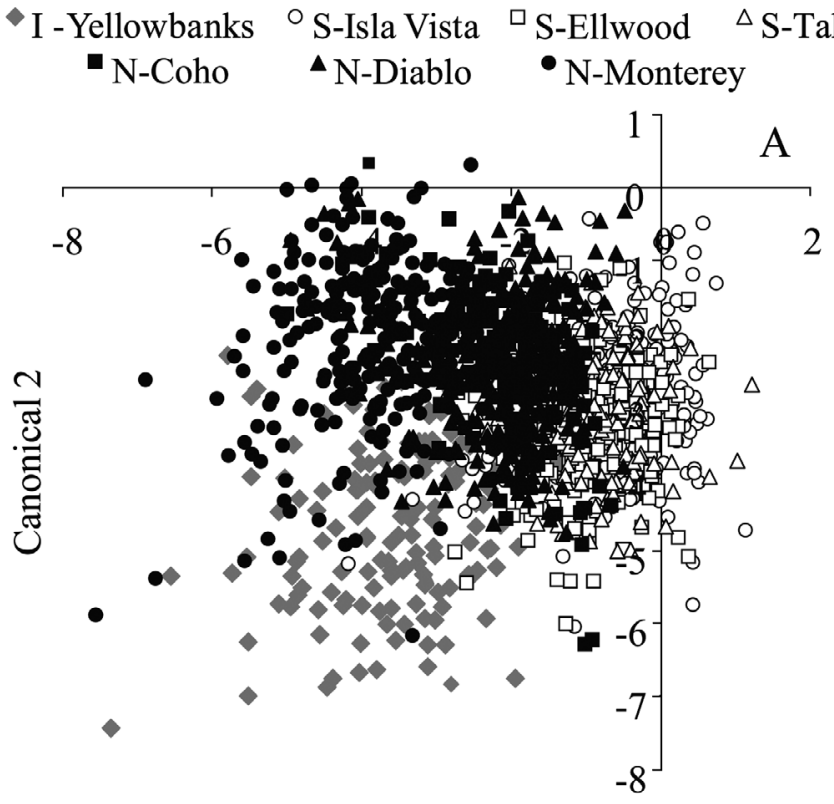

Canonical 1

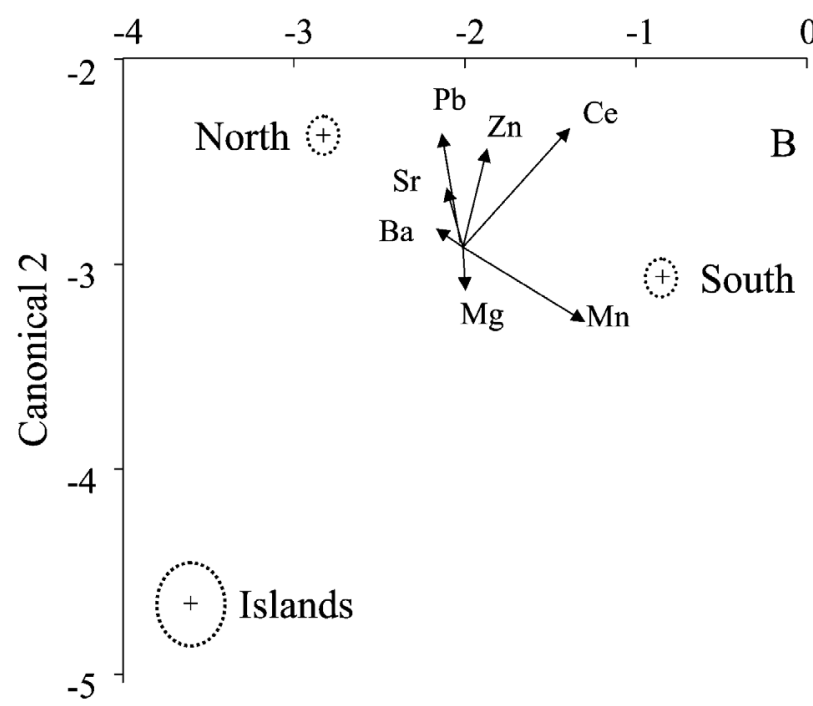

Canonical 1

Fig. 6. Kelletia kelletii. Discriminant scores summarizing variation in elemental composition of statoliths from encapsulated larvae formed during summer 2001 in 3 different regions: north (black symbols) versus south (open symbols) of Point Conception versus the Channel Islands (grey symbols). (A) Scatterplot of canonical scores; (B) biplot rays of standardized discriminant functions. Vectors indicate relative contributions of elements to canonical scores 

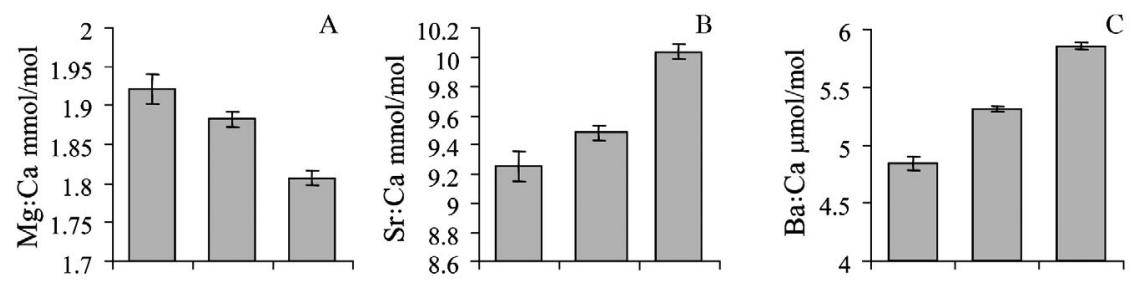

C Ba:Ca and $\mathrm{Pb}: \mathrm{Ca}$ ratios (Fig. $9 \mathrm{H}-\mathrm{N}$ ) relative to other years. As with the protoconchs, elemental tags of statoliths formed within a site can vary significantly in their chemical composition among years.
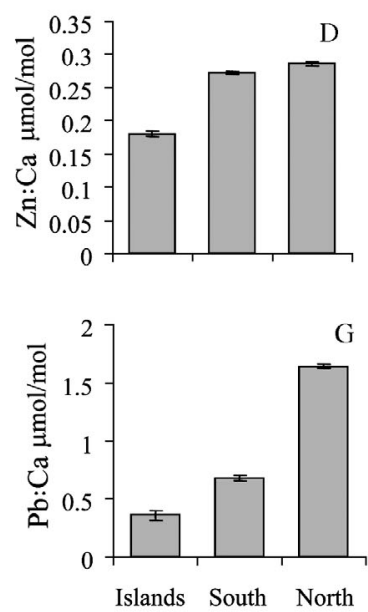
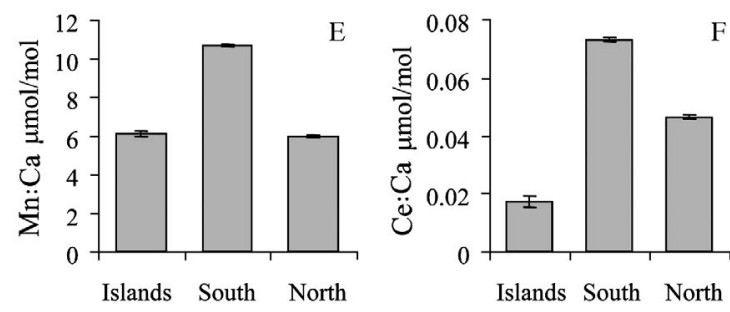

Fig. 7. Kelletia kelletii. Mean $( \pm 1$ SE) values of elements used in DFA to characterize natal signals in statoliths of encapsulated larvae for 3 regions during summer 2001: north versus south of Point Conception versus Channel Islands. Elements expressed as ratios to $\mathrm{Ca}$

ples differed significantly among all years $(\mathrm{p}<0.0001$ for all pair-wise comparisons; Table 9, Fig. 8B,D), and cross-validation accuracy was $83.1 \%$ (Table 9). The magnitude of the vectors of the standardized discriminant functions (Fig. 8D) indicated that, as with Ellwood, $\mathrm{Pb}: \mathrm{Ca}$, Ba:Ca and $\mathrm{Zn}: \mathrm{Ca}$, as well as $\mathrm{Mg}: \mathrm{Ca}$ played important roles in discriminating statolith samples among years at Monterey. Analyses of the elemental compositions of statoliths per year showed the lowest $\mathrm{Mg}: \mathrm{Ca}$ and $\mathrm{Zn}: \mathrm{Ca}$ and highest $\mathrm{Ce}: \mathrm{Ca}$ and $\mathrm{Pb}: \mathrm{Ca}$ ratios during 1999. Monterey statoliths from the year 2001 had the highest $\mathrm{Mg}: \mathrm{Ca}$ and $\mathrm{Zn}: \mathrm{Ca}$, but the lowest

Table 9. Kelletia kelletii. Cross-validation accuracy (\%) from linear discriminant-function analysis classifying statoliths to year of formation based on elemental composition. Columns identify year of statolith formation; rows identify percent of samples per site classified into each year based upon canonical scores

\begin{tabular}{|lccc|}
\hline Classification & 1999 & 2000 & 2001 \\
\hline Ellwood & & & \\
1999 & 94.4 & 10.7 & 0 \\
2000 & 5.6 & 78.0 & 7.6 \\
2001 & 0 & 11.3 & 92.4 \\
Overall accuracy = 88.4\% & & & \\
Monterey & 82.0 & 39.0 & 2.4 \\
1999 & 18.0 & 58.0 & 3.7 \\
2000 & 0.0 & 3.0 & 93.9 \\
2001 & & & \\
Overall accuracy = 83.1\% & & & \\
\hline
\end{tabular}
13.07, $r^{2}=0.77, p=0.050$, Fig. 10D). Finally, there was a statistically significant inverse relationship between per-site average temperature and $\mathrm{Ba}: \mathrm{Ca}$ ratios in both protoconchs $\left(y=-0.28+6.20, \mathrm{r}^{2}=0.87, \mathrm{p}=0.021\right.$, Fig. 10E) and statoliths $\left(y=-0.27+9.21, r^{2}=0.90\right.$, $\mathrm{p}=0.013$, Fig. 10F).

\section{DISCUSSION}

Previous work using elemental tags in fish otoliths opened a window on dispersal patterns of fishes (Campana 1999, Swearer et al. 1999, Thorrold et al. 2001). The results from this study suggest that there is also enough spatial variation in pre-release statolith and protoconch elemental compositions to provide regional and perhaps site-specific 'natal tags' in Kelletia kelletii larvae recruiting to populations in coastal environments. As with fish otoliths, natal tags in invertebrate larvae can be used to address questions about the dispersal patterns of marine invertebrates by assaying the larval shells or statoliths of new recruits.

\section{Variation among regions and sites}

What mechanisms generated the regional and sitespecific natal tags in Kelletia kelletii larvae? Differing elemental compositions in protoconchs and statoliths could reflect a variety of potential mechanisms, includ- 

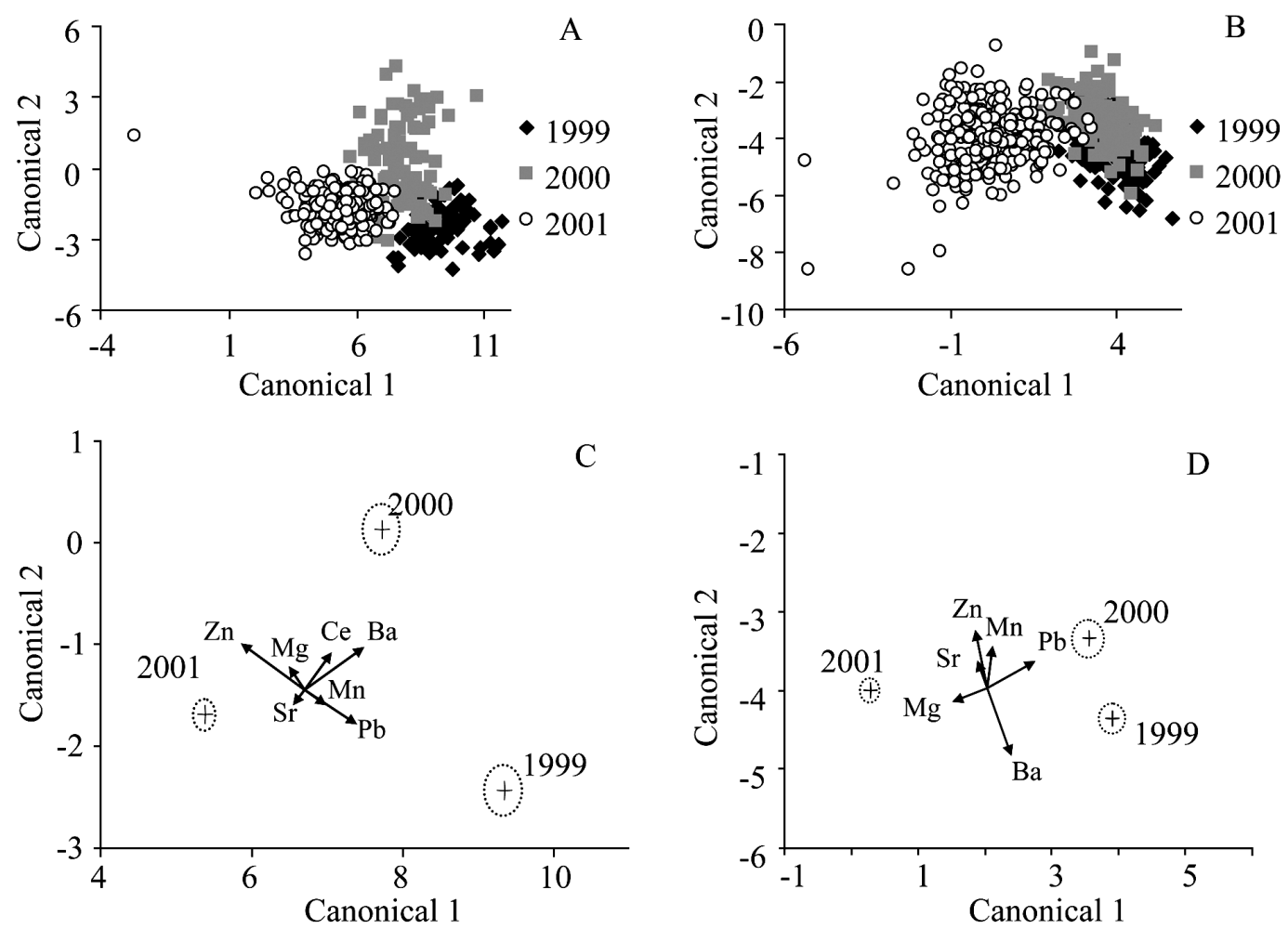

Fig. 8. Kelletia kelletii. Discriminant scores summarizing variation in the elemental composition of statoliths formed over 3 yr at Ellwood and Monterey. Scatterplot of canonical scores: (A) Ellwood; (B) Monterey. Biplot rays of standardized discriminant functions: (C) Ellwood; (D) Monterey. Vectors indicate relative contributions of elements to canonical scores
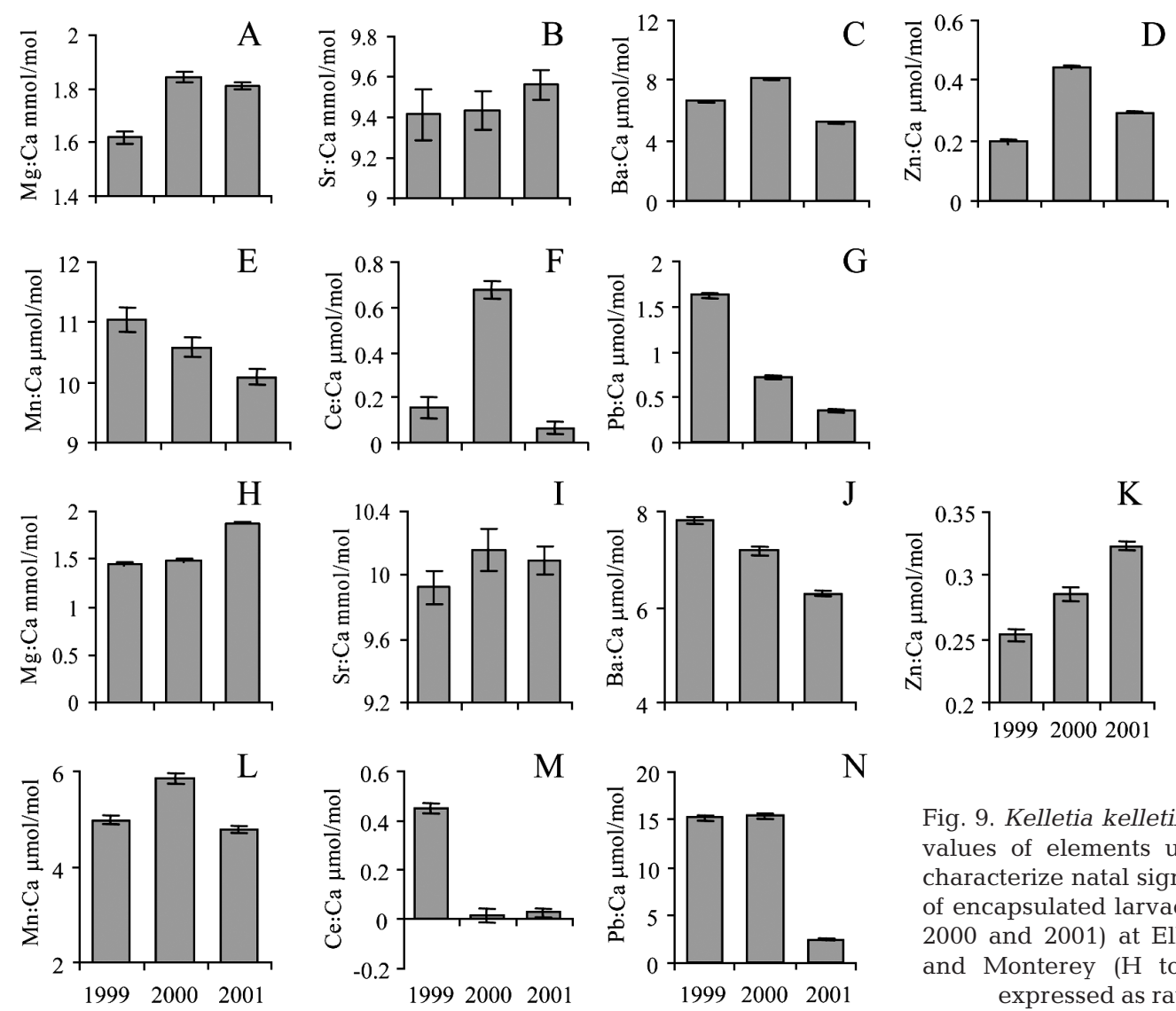

Fig. 9. Kelletia kelletii. Mean $( \pm 1 \mathrm{SE})$ values of elements used in DFA to characterize natal signals in statoliths of encapsulated larvae for 3 yr (1999, 2000 and 2001) at Ellwood (A to G) and Monterey ( $\mathrm{H}$ to $\mathrm{N})$. Elements expressed as ratios to $\mathrm{Ca}$ 

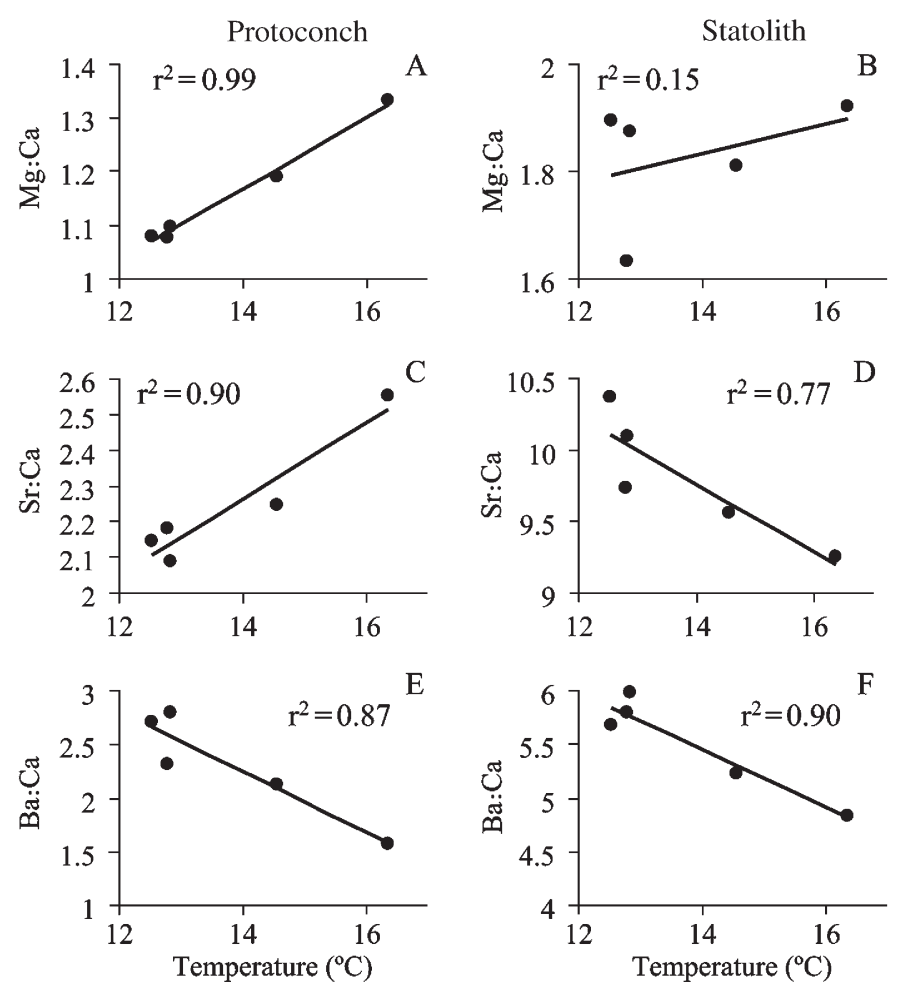

Fig. 10. Kelletia kelletii. Per site metal:Ca ratios as a function of average temperature in $2 \mathrm{wk}$ prior to field collections of larval statoliths and protoconchs showing linear regression lines

ing variation in elemental concentrations in seawater, seawater temperature, salinity, and variable precipitation rate (see Campana 1999 for review). In the absence of complete temporal and spatial physical-chemical sampling of water masses at each collection site, it is difficult to identify the exact mechanisms controlling the incorporation rates of each element measured. However, the regression analysis of subtidal temperature profiles (Table 1, Fig. 10) versus average per-site $\mathrm{Ba}: \mathrm{Ca}, \mathrm{Mg}: \mathrm{Ca}$ and $\mathrm{Sr}: \mathrm{Ca}$ ratios provides a starting point to compare whether the observed patterns of element incorporation into larval hard parts are consistent with known physical features of the environment. For example, in both statolith and protoconch of larval $K$. kelletii, Ba:Ca ratio was most elevated in the northern region and lowest at the island site (Figs. $3 \& 7$ ). This pattern is consistent with current knowledge about factors influencing $\mathrm{Ba}$ incorporation into biogenic aragonite and with known spatial patterns of oceanography in the region. First, Zacherl et al. (2003c) demonstrated that $\mathrm{Ba}$ is incorporated into aragonite statoliths and protoconchs of larval $K$. kelletii as a positive function of Ba seawater concentration and as an inverse function of temperature. That study represented the first conclusive demonstration of a temperature effect on $\mathrm{Ba}$ incorporation into an aragonitic structure. When average per-site temperature was regressed against average per-site protoconch and statolith Ba:Ca (Table 1, Fig. 10E,F), the strength of the inverse relationship between temperature and Ba incorporation was apparent. Second, Bath et al. (2000) demonstrated that $\mathrm{Ba}$ is incorporated into aragonitic fish otoliths in proportion to $\mathrm{Ba}$ seawater concentration. Elevated Ba in both mollusc shells (Stecher et al. 1996) and coral aragonite skeletons (Lea et al. 1989) also has been associated with periods of intense nutrient flux and upwelling, respectively. Ba in seawater follows a nutrient-like distribution; its main sources are river runoff and upwelling of Ba-rich deep water (Chan et al. 1977). Since the northern portion of the sampling region is most influenced by upwelling of cold seawater (Fig. 1, Table 1), the expectation is that $\mathrm{Ba}$ would be enriched in seawater, and hence in aragonite structures formed in this region. Whether temperature acts as the casual factor determining $\mathrm{Ba}$ incorporation into developing calcified structures in $K$. kelletii larvae or rather tightly co-varies with $\mathrm{Ba}$ concentration in seawater remains to be determined. Either way, it appears that relative temperature is a good qualitative predictor of relative $\mathrm{Ba}$ incorporation into both protoconchs and statoliths.

The observed pattern of the $\mathrm{Sr}$ :Ca ratio in Kelletia kelletii larval hard parts is more complex, but is consistent with laboratory culture experiments. Sr is generally considered conservative in seawater (but see de Villiers 1999), meaning that the Sr:Ca ratio in seawater remains constant relative to salinity. Although all the other elements showed consistent patterns of incorporation in statoliths and shells, Sr showed opposing patterns in the 2 aragonitic materials. The Sr:Ca ratio was elevated in northern statoliths compared to southern statoliths, but diminished in northern protoconchs relative to southern samples (Figs. $3 \& 7$ ). This was true both at the regional scale and when average per-site temperature was regressed against average per-site $\mathrm{Sr}: \mathrm{Ca}_{i} \mathrm{Sr}$ showed a negative correlation with temperature in statoliths, but co-varied positively with temperature in protoconchs (Fig. 10C,D). Other studies on $\mathrm{Sr}: \mathrm{Ca}$ incorporation rates as a function of temperature have been equally contradictory. Correlative field studies and empirical laboratory studies have reported positive (Bath et al. 2000), negative (Smith et al. 1979, Secor et al. 1995, Shen et al. 1996), nonlinear (Kalish 1989, Elsdon \& Gillanders 2002), contradictory (Stecher et al. 1996) and nonexistent (Gallahar \& Kingsford 1996) relationships between temperature and the $\mathrm{Sr}$ :Ca ratio in aragonite coral, shell and otolith. While inexplicable, the observed pattern of Sr incorporation into larval statoliths and protoconchs in this study is consistent with previous findings; in controlled larval $K$. kelletii culture studies, Zacherl (2003c) found the same appar- 
ently contradictory pattern as that observed in the field. Strontium incorporation into statoliths was an inverse function of temperature, while incorporation into protoconchs was a positive function of temperature.

Like $\mathrm{Sr}, \mathrm{Mg}$ has a generally conservative distribution in the world's oceans. However, Mg is incorporated into calcite foraminiferan tests (Nürnberg et al. 1996, Rosenthal et al. 1997, Lea et al. 1999) as a strong positive function of temperature. I also observed this positive temperature effect on $\mathrm{Mg}$ incorporation into protoconchs and statoliths in larval culture studies using several mollusk species including $K$. kelletii (D. C. Zacherl unpubl.). The $\mathrm{Mg}$ :Ca pattern observed in field-collected $K$. kelletii larvae at the regional scale is consistent with this temperature-sensitive relationship; the $\mathrm{Mg}: \mathrm{Ca}$ ratio was highest in the island samples where seawater temperature was warmest, and lowest in the samples from the colder northern region (Figs. 3 $\& 7)$. However, when temperature is regressed against Mg:Ca at the site scale, the relationship breaks down for statoliths, although it remains tightly positively correlated for protoconchs (Fig. 10A,B).

Relatively less is known about factors influencing incorporation rates of $\mathrm{Ce}, \mathrm{Mn}$, and $\mathrm{Pb}$, although the $\mathrm{Mn}$ :Ca ratio in coral aragonite is inversely related to upwelling intensity (Shen et al. 1991, Delaney et al. 1993), consistent with the occurrence of the lowest $\mathrm{Mn}$ :Ca ratio in the northern upwelling region. Lead $(\mathrm{Pb})$ shows a scavenged profile in the world's oceans: it is enriched in surface waters, and depleted with increasing depth. Of all the elements measured, it is most associated with industrial pollution, both from point-source runoff and from atmospheric deposition. Richardson et al. (2001) measured elevated Pb concentrations in mussel shells near known point-sources of $\mathrm{Pb}$ pollution. In K. kelletii larval hard parts, $\mathrm{Pb}$ :Ca was higher in the coastal regions than at the more isolated island site, which was less likely to be influenced by coastal runoff of $\mathrm{Pb}$. Confirmation of these qualitative patterns will require profiles of metal concentrations in seawater, and extends beyond the scope of this study.

It is perhaps important that the pathways for elements from seawater into statolith and protoconch are entirely different, with these elements crossing multiple and dissimilar biological membranes where elemental discrimination could take place. Thus, there is no a priori reason to expect statolith and protoconch to incorporate elements governed by the same mechanisms. This might partly explain why Sr could show opposite incorporation trends, and why Mg could be decoupled from temperature effects for statoliths but not for the protoconch. In the absence of additional knowledge about element concentrations in seawater, salinity and other factors influencing element incorpo- ration, the explanations for discrepant data in this study remain speculative. The contradictory patterns uncovered in this study further demonstrate the need for a much more complete temporal and spatial physical-chemical sampling of water masses relative to field-collected calcified structures. Finally, these discrepancies also point to the fact that when examining patterns of spatial variability, one cannot assume that one biogenic carbonate can serve as proxy for another without first completing the appropriate validation studies.

It is important to stress that it is not necessary to fully understand the mechanisms generating differences among regions to utilize this tool as a natal tag of origin; 2 conditions are necessary: (1) there must be predictable spatial variation in elemental composition of the target natal tag, and (2) the spatial variation must be sufficient to answer the question of interest. In the case of Kelletia kelletii, larval protoconchs and statoliths formed north of Point Conception were chemically distinguishable from those formed south of Point Conception. This suggests that natal tags contained within these aragonite structures could distinguish larvae produced in different regions and, hence, identify source-regions for settling larvae or new recruits. However, while the results discussed above represent a solid 'proof of concept' that statolith and protoconch chemistries vary on a regional scale, it will be necessary to more fully sample the entire range of this species to ensure the integrity of the regional tags as well as to explore the possibilities for using natural tags to trace dispersal trajectories over smaller spatial scales. In particular, the region including mainland sites south of Point Conception was only sampled within the Santa Barbara Channel, while the range of this species extends approximately $900 \mathrm{~km}$ further south into central Baja California, Mexico. Further, the Channel Islands 'region' is characterized by 1 site in this study. This ' 1 site' region is a side-effect of the extremely low reproductive output at the Channel Islands sites relative to the mainland sites, where 3 of 4 Channel Islands sites (see 'Materials and methods' and Fig. 1) yielded no egg-laying activity compared to all mainland sites yielding reproductive activity. Such evidence suggests that the Channel Islands sites are not an important source of larvae, but makes it difficult to characterize the Channel Islands chemical fingerprint.

In this study, the predictive capacity of the DFA was reasonably high even at the level of sites. It was especially promising that, in the case of protoconchs, the misclassified samples were most often assigned to a nearest neighbor. It is not clear why this pattern did not also hold for statoliths. These data suggest that natural tags may be effective tags of natal source even at spatial scales as small as $10 \mathrm{~km}$ (the distance between 
the population at Ellwood and its nearest northern and southern neighbors, Isla Vista and Tajiguas). However, despite the reasonably high accuracy of assignment to site in these preliminary studies, the conclusion that natural tags can be used to define dispersal at finer spatial scales than regional is premature. In order to use natural tags to examine movements with fine resolution, it is critical to characterize a much higher fraction of potential source populations or to understand the physical mechanisms generating among-site differences well enough to predict the chemistry of calcified structures from unsampled populations. Despite these caveats, the data from this study provide provocative evidence that the hard parts of open-coast invertebrate larvae can contain naturally produced tags of natal source.

\section{Variation among broods}

Although the mechanisms generating among-region differences are consistent with known oceanographic conditions, the mechanisms generating significant variation among broods within sites remain unknown. Conceivably, small-scale variation in seawater characteristics could be large enough to generate within-site differences in broods, although broods from a particular site were generally collected within $100 \mathrm{~m}$ distance of each other. Alternatively, female nutritional status (e.g. as a result of differences in yolk contribution) or genetic effects could significantly influence statolith and protoconch chemistry. Clearly, more studies are required to differentiate the mechanisms generating among-brood variation.

\section{Variation among years}

This study found significant temporal variability in the chemical composition of larval hard parts within sites among years (Figs. 4 \& 8, Tables 4 \& 8). This temporal variation suggests that the most conservative approach for characterizing sites of larval origin would require annual surveys of the spatial pattern of hardpart chemistry in pre-release larvae. In this way, natal tags isolated from subsequently recruited individuals could be matched directly to samples from pre-release larvae of the same cohort. This conservative approach might be necessary, but is clearly not ideal, as the costs associated with massive annual sampling of prerelease larvae from all possible source-regions could quickly become prohibitive. However, if variation among regions is sufficiently large enough to consistently overcome within-site temporal variation, it might be possible to generate a useful multi-year pre- dictive model using just a single year's larval samples. As a preliminary test of whether a linear discriminantfunction analysis (DFA) generated using only a single year's samples might serve as a useful predictive model for other years, I characterized 1999 and 2000 samples from Ellwood and Monterey using the statolith and protoconch DFA analyses built using just 2001 data. Despite significant variation among years, the DFA generated using only 2001 data predicted the region of origin correctly for $100 \%$ of statolith and protoconch samples from Monterey (Table 10) and $\geq 65 \%$ of protoconch and statolith samples from Ellwood. The overall accuracy for both DFA models was $>82 \%$. In the southern region, clearly the most accurate DFA would be built using pre-release larvae from the same cohort as the recruits in question. However, in the case of the northern region, despite significant among-year variation in the chemical composition of statoliths and protoconchs, spatial variation is sufficiently large to overcome errors from interannual differences. This suggests that it may be possible to generate a reasonably accurate predictive model using a single year's collection of pre-release larvae. Nonetheless, the most robust, conservative and recommended approach would build a predictive model based upon a 'library of elemental fingerprints' collected over several years (Gillanders 2002).

This study did not examine intra-annual variation in statolith and protoconch composition. Gillanders (2002) reviewed a series of papers that examined such variation, and concluded that in regions where there is little variation in rainfall and other freshwater inputs, temporal variation is likely to be minimal, but cannot be discounted without empirical testing. Given that

Table 10. Kelletia kelletii. Cross-validation accuracy from linear discriminant-function analysis classifying protoconchs and statoliths formed in 1999 and 2000 into the correct region of formation using only 2001 data to build the predictive model. Columns identify year of protoconch and statolith formation. Rows identify percent of samples per year classified into each region

\begin{tabular}{|c|c|c|c|c|}
\hline \multirow[t]{2}{*}{ Classification } & \multicolumn{2}{|c|}{ Protoconch } & \multicolumn{2}{|c|}{ Statolith } \\
\hline & 1999 & 2000 & 1999 & 2000 \\
\hline \multicolumn{5}{|l|}{ Ellwood } \\
\hline $\mathrm{N}$ & 70.0 & 0.0 & 26.7 & 34.0 \\
\hline $\mathrm{S}$ & 30.0 & 100.0 & 73.3 & 63.3 \\
\hline I & 0.0 & 0.0 & 0.0 & 2.7 \\
\hline Overall accuracy & \multicolumn{2}{|c|}{$65 \%$} & \multicolumn{2}{|c|}{$67 \%$} \\
\hline \multicolumn{5}{|l|}{ Monterey } \\
\hline $\mathrm{N}$ & 100.0 & 100.0 & 100.0 & 100.0 \\
\hline $\mathrm{S}$ & 0.0 & 0.0 & 0.0 & 0.0 \\
\hline I & 0.0 & 0.0 & 0.0 & 0.0 \\
\hline Overall accuracy & \multicolumn{2}{|c|}{$100 \%$} & \multicolumn{2}{|c|}{$100 \%$} \\
\hline Total accuracy & \multicolumn{2}{|c|}{$82.5 \%$} & \multicolumn{2}{|c|}{$83.9 \%$} \\
\hline
\end{tabular}


across the entire range of Kelletia kelletii, spawning occurs only over a short window of time (summer) during which freshwater inputs are effectively nonexistent along the entire range of this species, intra-annual variation in hard-part composition is probably not of concern. However, this possibility cannot be discounted without further studies specifically targeting variation within a site and within a spawning period.

\section{Identifying sources of post-settlement individuals}

An interesting development in this species' recent past illustrates the critical importance for understanding its dispersal history. In the past few decades, Kelletia kelletii has extended its range (Herrlinger 1981) from its historic northern limit at Point Conception to its present limit in Monterey Bay. This $325 \mathrm{~km}$ northward expansion (Fig. 1) occurred during a period of both seawater warming (Barry et al. 1995) and substantial variation in ocean circulation in response to several large El Niño events. In addition to being a headland where major ocean currents collide, Point Conception is also a major biogeographic boundary and coincident range limit for many marine taxa (Newman 1979, Morris et al. 1980, Doyle 1985).

What change enabled the range extension of Kelletia kelletii and what factors affect persistence of those recently established northern populations? The populations north of Point Conception exhibit sporadic recruitment pulses (Zacherl et al. 2003a) that may be due to limits on northward dispersal of larvae (Haury et al. 1986) by prevailing current conditions during their reproductive season (Harms \& Winant 1998). Are northern populations reliant upon larvae from sources south of Point Conception for their persistence? A tool that could identify the source of $K$. kelletii recruits would be able to test this hypothesis directly by identifying the regional source of production of recruiting larvae. Since calcified structures formed in developing larvae north of Point Conception are chemically distinguishable from those produced to the south, the extent of spatial variation in chemistry appears to be sufficient to use this tracer tool to identify regional sources of incoming $K$. kelletii recruits.

Use of this new tool relies upon the ability to analyze the natal tag in post-settlement individuals using techniques similar to those developed for otolith analyses. Settlers are collected, their statoliths are then removed and/or protoconchs are isolated. The natal portions of these hard parts can then be ablated using an ablation system with a nominal beam-width whose resolution is smaller than the diameter of the natal core (e.g. $5 \mu \mathrm{m}$ beam width, see Thorrold \& Shuttleworth 2000). The resultant elemental signal could elucidate source- region information. In this study, protoconchs were pooled and analyzed via solution-based methods to enhance detection of trace elements. In order to use protoconchs as natal tags, it would be necessary to analyze single protoconchs. Methods to analyze single protoconchs via laser-based techniques are now established (Becker et al. 2005), greatly increasing the feasibility for using protoconchs as natal tags. The remaining challenge is to assign post-settlement individuals to the correct recruitment cohort through aging studies. This requires the demonstration that statoliths, like otoliths, function as time-keeping devices, enabling correct assignment to cohort.

The use of the elemental signals in larval statoliths and protoconchs as 'tags' of source could be an important tool for examining connectivity among marine populations. The existence of significant spatial variability in the elemental composition of Kelletia kelletii larval protoconchs and statoliths suggests that natal tags could distinguish larvae produced in different regions, and hence hold promise for identifying source-regions for settling larvae.

Acknowledgements. This is contribution number 160 of the Partnership for Interdisciplinary Studies of Coastal Oceans (PISCO), a long-term ecological consortium funded by the David and Lucile Packard Foundation. This research was also funded by grants from the National Science Foundation (OCE-0351860), CEQI (Coastal Environmental Quality Initiative), Sigma $\mathrm{Xi}$, and Lerner-Gray Foundation. Thanks to $\mathrm{S}$. Swearer, G. Paradis, D. Lea, S. Gaines, R. Warner, and A. Kuris for providing valuable training and guidance. Thanks to many dive buddies, technicians, post-docs, and support staff including S. Lonhart, C. Faist, B. Cheng, A. Haupt, S. Kleinshmidt, J. Van Leuven, M. Salonga, A. Hsu, B. Wolcott, A. Pappas, E. Tanadjaja, C. Svedlund, T. Jenkins, C. Mangiardi, A. Wyndham, B. and S. Best, E. Hessel, M. Hickford, M. Gomez, M. Behrens, C. Gotshalk, J. Caselle, D. Pak, C. Cudaback, S. Anderson, and T. Marciando. Three anonymous reviewers provided thoughtful feedback on an earlier draft of this manuscript. Finally, thanks to the researchers at TENERA for providing valuable access to samples from Diablo Canyon.

\section{LITERATURE CITED}

Anastasia JC, Morgan SG, Fisher NS (1998) Tagging crustacean larvae: assimilation and retention of trace elements. Limnol Oceanogr 43:362-368

Barry JP, Baxter CH, Sagarin RD, Gilman SE (1995) Climaterelated long-term faunal changes in a California rocky intertidal community. Science 267:672-675

Bath GE, Thorrold SR, Jones CM, Campana SE, McLaren JW, Lam JWH (2000) Sr and Ba uptake in aragonitic otoliths of marine fish. Geochim Cosmochim Acta 64:1705-1714

Becker BJ, Fodrie FJ, McMillan P, Levin LA (2005) Spatial and temporal variation in trace elemental fingerprints of mytilid mussel shells: a precursor to invertebrate larval tracking. Limnol Oceanogr 50:48-61

Caley MJ, Carr MH, Hixon MA, Hughes TP, Jones GP, 
Menge BA (1996) Recruitment and the local dynamics of open marine populations. Annu Rev Ecol Syst 27:477-500

Campana SE (1999) Chemistry and composition of fish otoliths: pathways, mechanisms and applications. Mar Ecol Prog Ser 188:263-297

Chan LH, Drummond D, Edmund JM, Grant B (1977) On the barium data from the Atlantic GEOSECS expedition. DeepSea Res 24:613-649

Crowder LB, Lyman SJ, Figueira WF, Priddy J (2000) Sourcesink population dynamics and the problem of siting marine reserves. Bull Mar Sci 66:799-820

Delaney ML, Linn LJ, Druffel ERM (1993) Seasonal cycles of manganese and cadmium in coral from the Galápagos Islands. Geochim Cosmochim Acta 57:347-354

Dever EP, Hendershott C, Winant CD (1998) Statistical aspects of surface drifter observations in the Santa Barbara Channel. J Geophys Res 103:24781-24797

de Villiers S (1999) Seawater strontium and Sr/Ca variability in the Atlantic and Pacific oceans. Earth Planet Sci Lett 171:623-634

DiBacco C, Levin LA (2000) Development and application of elemental fingerprinting to track the dispersal of marine invertebrate larvae. Limnol Oceanogr 45:871-880

Doyle RF (1985) Biogeographical studies of rocky shores near Point Conception, California. PhD dissertation, University of California, Santa Barbara

Elsdon TS, Gillanders BM (2002) Interactive effects of temperature and salinity on otolith chemistry: challenges for determining environmental histories of fish. Can J Fish Aquat Sci 59:1796-1808

Gaines SD, Gaylord B, Largier JL (2003) Avoiding current oversights in marine reserve design. Ecol Appl 13:S32-S46

Gallahar NK, Kingsford MJ (1996) Factors influencing Sr/Ca ratios in otoliths of Girella elevata: an experimental investigation. J Fish Biol 48:174-186

Gillanders BM (2002) Temporal and spatial variability in elemental composition of otoliths: implications for determining stock identity and connectivity of populations. Can J Fish Aquat Sci 59:669-679

Gillanders BM, Kingsford MJ (1996) Elements in otoliths may elucidate the contribution of estuarine recruitment to sustaining coastal reef populations of a temperate reef fish. Mar Ecol Prog Ser 141:13-20

Harms S, Winant CD (1998) Characteristic patterns of the circulation in the Santa Barbara Channel. J Geophys Res 103:3041-3065

Haury LR, Simpson JJ, Pelaez J, Koblinsky CJ, Wiesenhahn D (1986) Biological consequences of a recurrent eddy off Point Conception, California. J Geophys Res 91: 12937-12956

Hayward TL, Cayan DR, Franks PJS, Lynn RJ and 5 others (1995) The state of the California current in 1994-1995-a period of transition. Calif Coop Ocean Fish Investig Rep 36:19-39

Herrlinger TJ (1981) Range extension of Kelletia kelletii. Veliger 24:78

Jones GP, Milicich MJ, Emslie MJ, Lunow C (1999) Selfrecruitment in a coral reef fish population. Nature 402: 802-804

Kalish JM (1989) Otolith microchemistry: validation of the effects of physiology, age and environment on otolith composition. J Exp Mar Biol Ecol 132:151-178

Lea DW, Shen GT, Boyle EA (1989) Coralline barium records temporal variability in equatorial Pacific upwelling. Nature 340:373-376

Lea DW, Mashiotta TA, Spero HJ (1999) Controls on magnesium and strontium uptake in planktonic foraminifera determined by live culturing. Geochim Cosmochim Acta 63:2369-2379

Levin LA (1990) A review of methods for labeling and tracking marine invertebrate larvae. Ophelia 32:115-144

Morris RH, Abbott DP, Haderlie EC (1980) Intertidal invertebrates of California. Stanford University Press, Stanford, CA

Newman WA (1979) Californian transition zone: significance of short-range endemics. In: Gray J, Boucot AJ (eds) Historical biogeography, plate tectonics, and the changing environment. Oregon State University Press, Corvallis, OR, p 399-416

Nürnberg D, Bijma J, Hemleben C (1996) Assessing the reliability of magnesium in foraminiferal calcite as a proxy for water temperatures. Geochim Cosmochim Acta 60: 803-814

Patterson HM, Thorrold SR, Shenker JM (1999) Analysis of otolith chemistry in Nassau grouper (Epinephelus striatus) from the Bahamas and Belize using solution-based ICPMS. Coral Reefs 18:171-178

Radtke RL, Shafer DJ (1992) Environmental sensitivity of fish otolith microchemistry. Aust J Mar Freshw Res 43: 935-951

Richardson CA, Chenery SRN, Cook JM (2001) Assessing the history of trace metal $(\mathrm{Cu}, \mathrm{Zn}, \mathrm{Pb})$ contamination in the North Sea through laser ablation-ICP-MS of horse mussel Modiolus modiolus shells. Mar Ecol Prog Ser 211: $157-167$

Rosenthal RJ (1970) Observations on the reproductive biology of the Kellet's whelk, Kelletia kelletii. Veliger 12:319-324

Rosenthal Y, Boyle EA, Slowey N (1997) Temperature control on the incorporation of $\mathrm{Mg}, \mathrm{Sr}, \mathrm{F}$ and $\mathrm{Cd}$ into benthic foraminiferal shells from Little Bahama Bank: prospects for thermocline paleoceanography. Geochim Cosmochim Acta 61:3633-3643

Rosenthal Y, Field MP, Sherrell RM (1999) Precise determination of element/calcium ratios in calcareous samples using sector field inductively coupled plasma mass spectrometry. Anal Chem 71:3248-3253

Secor DH, Henderson-Arzapalo A, Piccoli PM (1995) Can otolith microchemistry chart patterns of migration and habitat utilization in anadromous fishes? J Exp Mar Biol Ecol 192:15-33

Shen CC, Lee T, Chen CY, Wang CH, Dai CF, Li LA (1996) The calibration of $\mathrm{D}^{[\mathrm{Sr} / \mathrm{Ca}]}$ versus sea surface temperature relationship for Porites corals. Geochim Cosmochim Acta 60:3849-3858

Shen GT, Campbell TM, Dunbar RB, Wellington GM, Colgan MW, Glynn PW (1991) Paleochemistry of manganese in corals from the Galapagos Islands. Coral Reefs 10:91-100

Smith SV, Buddemeier RW, Redalje RC, Houck JE (1979) Strontium-calcium thermometry in coral skeletons. Science 204:404-407

Stecher HA III, Krantz DE, Lord CJ III, Luther GW III, Bock KW (1996) Profiles of strontium and barium in Mercenaria mercenaria and Spisula solidissima shells. Geochim Cosmochim Acta 60:3445-3456

Stobutzki IC, Bellwood DR (1997) Sustained swimming abilities of the late pelagic stages of coral reef fishes. Mar Ecol Prog Ser 149:35-41

Swearer SE, Caselle JE, Lea DW, Warner RR (1999) Larval retention and recruitment in an island population of a coral reef fish. Nature 402:799-802

Swearer SE, Forrester GE, Steele MA, Brooks AJ, Lea DW (2003) Spatio-temporal and interspecific variation in otolith trace-elemental fingerprints in a temperate estuarine fish assemblage. Estuar Coast Shelf Sci 56:1111-1123 
Thorrold SR, Shuttleworth S (2000) In situ analysis of trace elements and isotope ratios in fish otoliths using laser ablation sector field inductively coupled plasma mass spectrometry. Can Fish Aquat Sci 57:1232-1242

Thorrold SR, Jones CM, Campana SE, McLaren JW, Lam JWH (1998) Trace element signatures in otoliths record natal river of juvenile American shad (Alosa sapidissima). Limnol Oceanogr 43:1826-1835

Thorrold SR, Latkoczy C, Swart PK, Jones CM (2001) Natal homing in a marine fish metapopulation. Science 29:297-299

Thorrold SR, Jones GP, Hellberg ME, Burton RS, Swearer SE, Neigel JE, Morgan SG, Warner RR (2002) Quantifying larval retention and connectivity in marine populations with artificial and natural markers. Bull Mar Sci 70: 291-308

Warner RR, Swearer SE, Caselle JE (2000) Larval accumulation and retention: implications for the design of marine

Editorial responsibility: Lisa Levin (Contributing Editor), La Jolla, California, USA reserves and essential fish habitat. Bull Mar Sci 66: $821-830$

Young CM (1995) Behavior and locomotion during the dispersal phase of larval life. In: McEdward L (ed) Ecology of marine invertebrate larvae. CRC Press, Boca Raton, FL, p 249-278

Zacherl DC, Gaines S, Lonhart S (2003a) The limits to biogeographical distributions: insights from the northward range extension of the marine snail, Kelletia kelletii (Forbes, 1852). J Biogeogr 30:913-924

Zacherl DC, Manríquez PH, Paradis G, Day RW, Castilla JC, Warner RR, Lea DW, Gaines SG (2003b) Trace elemental fingerprinting of gastropod statoliths to study larval dispersal trajectories. Mar Ecol Prog Ser 248:297-303

Zacherl DC, Paradis G, Lea DW (2003c) Barium and strontium uptake into larval protoconchs and statoliths of the marine neogastropod Kelletia kelletii. Geochim Cosmochim Acta 67:4091-4099

Submitted: November 30, 2003; Accepted: October 11, 2004 Proofs received from author(s): March 24, 2005 